\title{
THE FEASIBILITY OF AN 8-WEEK, HOME-BASED ISOMETRIC STRENGTH TRAINING PROGRAM FOR IMPROVING DRESSAGE TEST PERFORMANCE IN EQUESTRIAN ATHLETES
}

\author{
Jordan Talmadge Lee
}

A thesis submitted to the faculty of the University of North Carolina at Chapel Hill in fulfillment of the requirements for the degree of Masters of Arts in the Department of Exercise and Sport Science (Exercise Physiology).

\section{Chapel Hill}

2015

Approved By:

Claudio L. Battaglini

Anthony C. Hackney

Edgar W. Shields

Eric J. Soboleswki 
(C) 2015

Jordan Talmadge Lee

ALL RIGHTS RESERVED 


\begin{abstract}
Jordan Lee: The Feasibility of an 8-week, Home-based Isometric Strength Training Program for Improving Dressage Test Performance in Equestrian Athletes

(Under the direction of Dr. Claudio L. Battaglini)

PURPOSE: To determine the feasibility of an 8-week, home-based isometric strength-training program in equestrians. Secondary purposes examined changes in muscular strength, endurance, and riding performance. METHODS: 18 riders ( $\geq 1 \mathrm{yr}$ dressage experience, riding $\geq 1 \mathrm{hr} /$ week, otherwise untrained) completed pre/post muscular tests and a US Equestrian Federation (USEF) Training Level Rider Test. A progressive, 3 day/wk riding-specific intervention using Therabands was implemented. Feasibility was determined as $>50 \%$ of riders completing $\geq 18 / 24$ sessions of $\geq 2$ sets/exercise of prescribed volume. Dependent samples t-tests compared pre/post composite muscular strength/endurance, and riding test scores. RESULTS: $55.5 \%$ of riders completed $\geq 75 \%$ exercise sessions. Significant improvements were observed for muscular endurance ((pre 149.8 \pm 82.2 , post $209.2 \pm 112.2), \mathrm{p}=.003)$, and for riding test scores ((pre $57.8 \pm 7.4$, post $60.8 \pm 5.1), \mathrm{p}=.037)$. Exploratory analyses revealed a significant correlation between improvements in muscular endurance and riding test score $\left(\mathrm{r}^{2}=.285, \mathrm{p}=.02\right)$. CONCLUSION: The intervention was feasible and produced improvements in muscular strength, endurance, and riding test performance.
\end{abstract}


To my mother, the strongest woman I know, for putting her whole heart into supporting my every dream and endeavor.

In memory of my best friend, Candace Newmaker: may the short life you lived remind us of the delicacy and opportunity we have in our own. 


\section{TABLE OF CONTENTS}

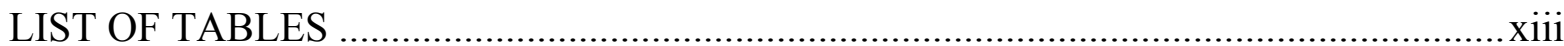

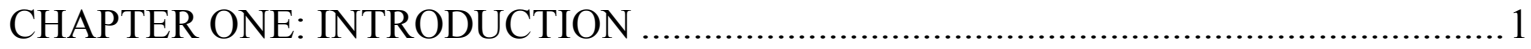

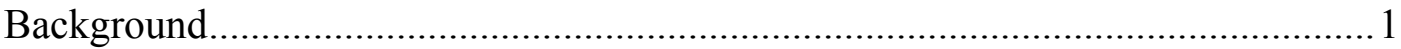

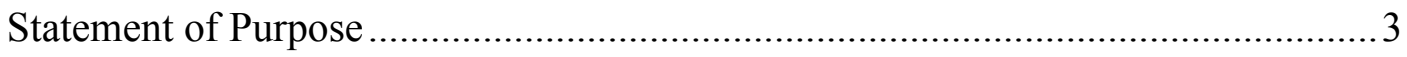

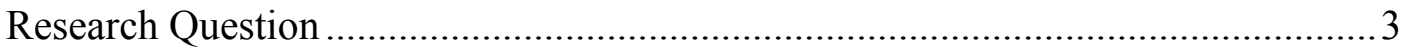

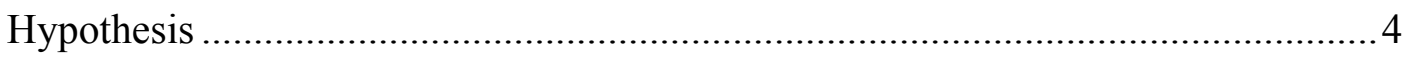

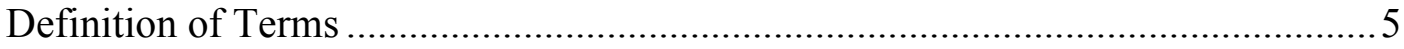

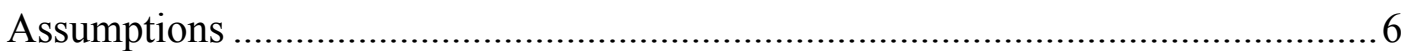

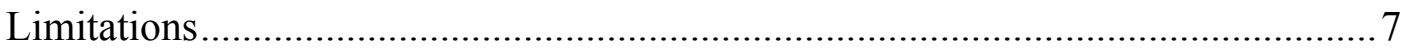

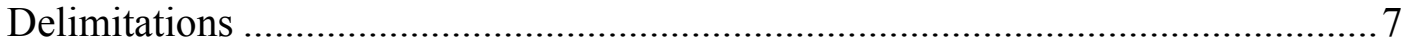

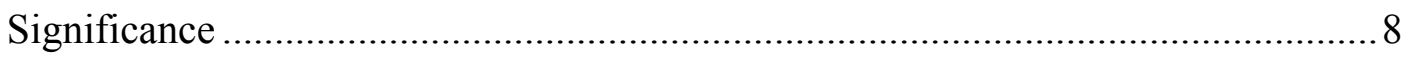

CHAPTER TWO: REVIEW OF LITERATURE ................................................... 9

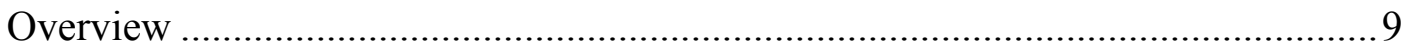

Sport of Horseback Riding .................................................................. 9

Horse and Rider Communication and Rider Positioning ...................................... 10

Physical Fitness of the Equestrian Athlete ...................................................... 11

Demands and Movement Patterns of Equestrians ............................................. 14

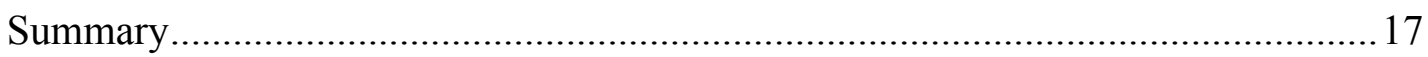

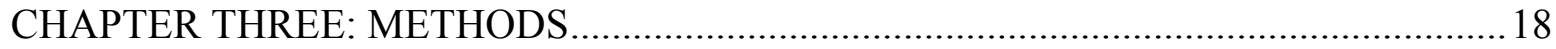

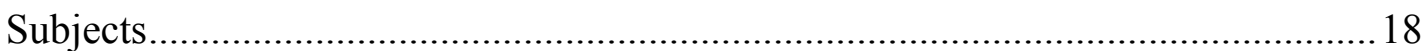




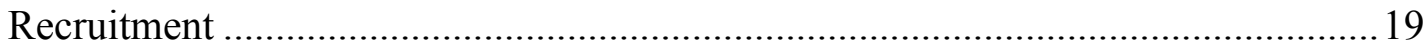

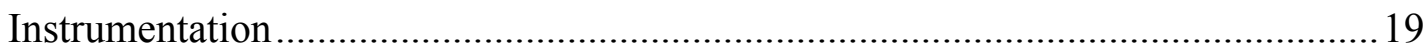

Research Design Overview …………………………....................................2

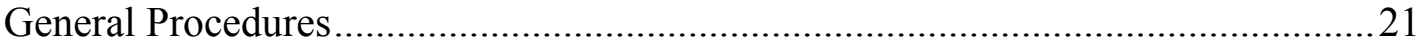

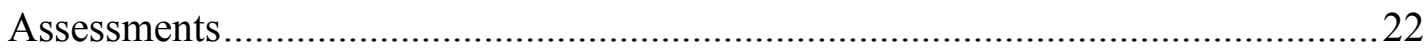

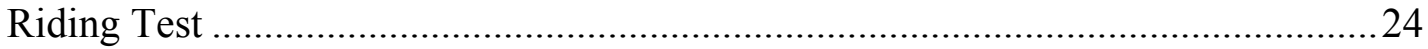

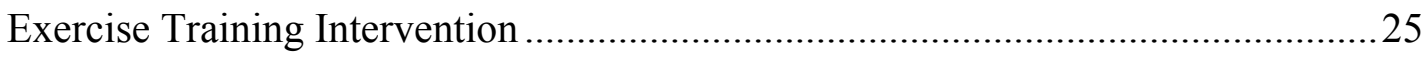

Statistical Analysis and Design ......................................................................28

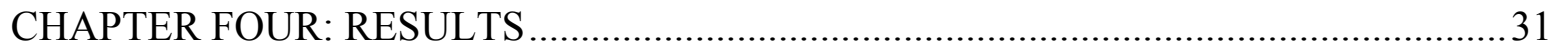

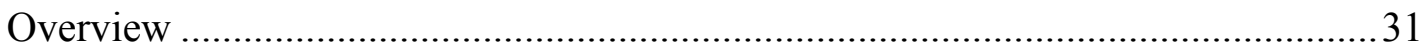

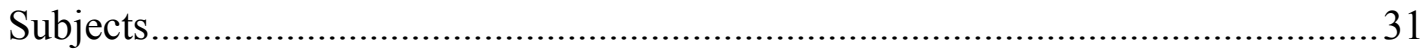

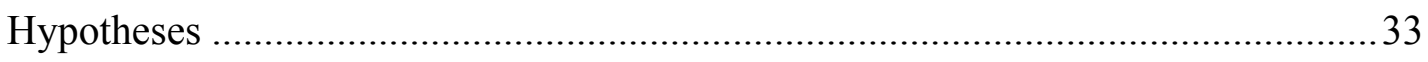

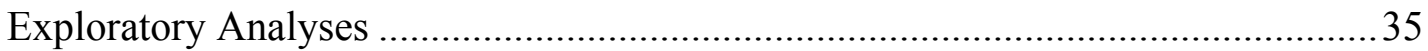

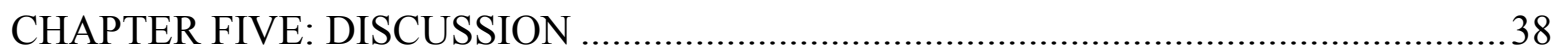

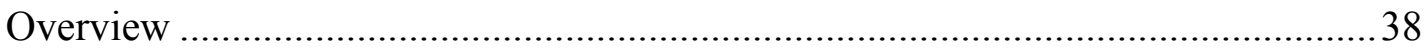

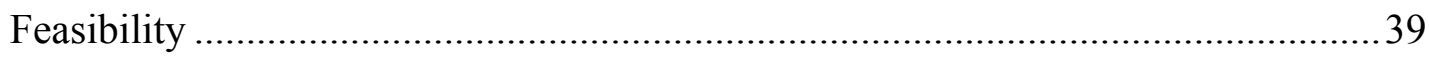

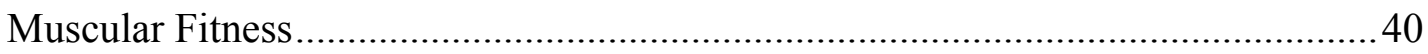

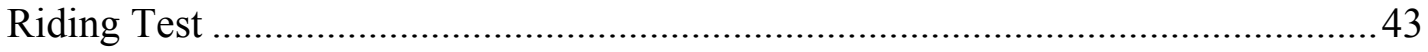

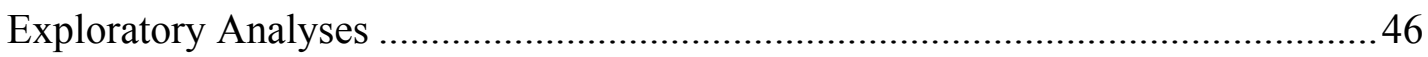

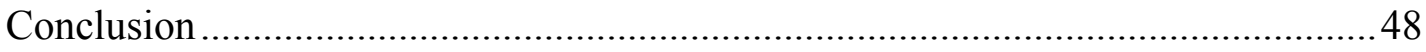

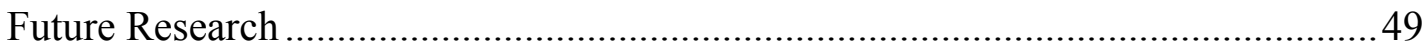

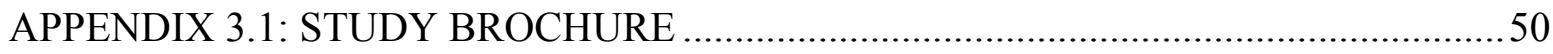

APPENDIX 3.2: PRE-ASSESSMENT GUIDELINES ………………………..............51 
APPENDIX 3.3: PHYSICAL ACTIVITY READINESS QUESTIONNAIRE (PARQ) .....52

APPENDIX 3.4: MEDICAL HISTORY QUESTIONNAIRE

APPENDIX 3.5:INTERNATIONAL PHYSICAL

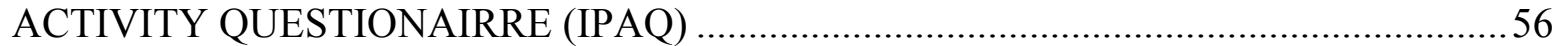

APPENDIX 3.6: USEF TRAINING LEVEL RIDER TEST ………………………….......... 60

APPENDIX 3.7: PRE-ASSESMENT QUESTIONAIRRE ………………………….......... 62

APPENDIX 3.8: STANDARD/SMALL DRESSAGE ARENA ……………………..........63

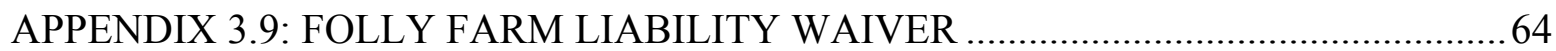

APPENDIX 3.10: PARTICIPANT EXERCISE INSTRUCTION MANUAL ......................65

APPENDIX 3.11: PARTICIPANT EXERCISE LOG ……………………………............ 71

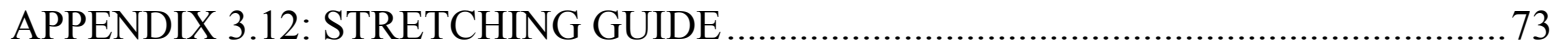

APPENDIX 3.13: INTERVENTION ENJOYMENT QUESTIONAIRRE...........................74

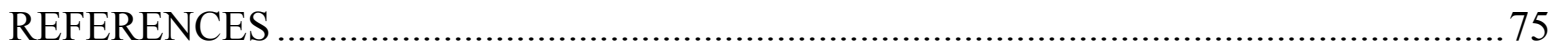




\section{LIST OF TABLES}

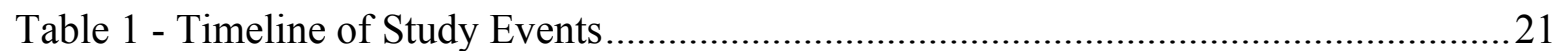

Table 2 - Progression of Strength Training Over the 8-week Intervention .........................2 27

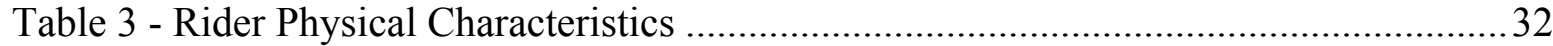

Table 4 - Physical Fitness and Riding Test Performance Scores .................................... 33 


\section{CHAPTER 1: INTRODUCTION}

\section{Background}

The horse industry, with about 4.6 million people involved, produces a total economic impact of $\$ 101.5$ billion on the United States’ Gross Domestic Product (GDP). Of that, approximately $\$ 10-\$ 12$ billion are from riding activities alone. The horse business is highly diverse with rural to urban activities, breeding and training to high dollar races and shows. The sport is unique in that it involves a partnership between a human and a relatively "wild" animal of drastically different sizes. The sport is also distinct in that men and women compete side by side, although the field is dominated by female participants $(\sim 85 \%)$. American equestrians tend to be older, with an average age of 39 years old ("National economic impact", 2005). Some equestrians participate for pleasure and others train for competitions.

The physical demands on the horse are relatively obvious, yet, the physical demands on the rider are highly debatable and very understudied. Due to the array of equestrian disciplines (western, carriage driving, saddleseat, etc.), the specificity of physical demands of the rider to perform vary significantly by different disciplines. To date, very little has been studied regarding

the potential that improving specific physical attributes of the rider potentially having an impact on the overall riding performance. In dressage, a horseback modality where the rider's capacity to maintain proper position, balance and connection with the horse, may be dependent on the rider's ability to maintain isometric muscular contractions for an extended period of time. Improving this muscular capacity may translate into better riding performance. 
Dressage is the performance of a horse and rider completing a series of predetermined movements of varying difficulty. Dressage is commonly referred to as "horse ballet" because the horse and rider appear to dance together. The performance spectrum ranges from simple patterns with minimal gait and directional changes to complex patterns where the rider instructs the horse to pivot, extend, move laterally and move backwards with precision, ease and power. Movements are graded from 0-10 by a certified judge using the Federation Equestre Internationale (FEI) guidelines (FEI, 2013). Like gymnastics, judging is subjective and controversy about scores is prevalent. Means to objectively measure horse and rider 'harmony' have been determined, yet the methods are far too impractical to implement in a real-world show setting. These methods are purposeful for education and training of judges and instructors (Peham 2001). Judges usually evaluate the horse's performance in a dressage test. However, in 2012 the United States Equestrian Federation (USEF) created Rider Tests to assess the rider's performance.

Although research in this field is limited, a few published studies have concluded that riding alone only minimally improves equestrian fitness and that cross-training is necessary to reach optimal physiological fitness (Devienne, 2000; Meyers, 2000; Meyers, 2006). Traditionally, cross-training is not a habit of most equestrians. However, improved fitness gained through cross-training may lead to improved riding performance by allowing the rider to maintain a more stable and balanced position while performing the required equitation movements. Due to the additional time required to care for horses outside of just riding (trailering to/from training, mucking stalls, cleaning tack, moving hay, etc.), equestrians may not have the time to invest in traveling to an exercise facility to participate in training programs that could potentially assist them in improving their quality of riding and consequently, perform 
better in competition. Therefore, examining the feasibility of providing riders with an exercise intervention where they could participate during a convenient time and location (for example at home) aimed to improve physical fitness for horseback riding is warranted. The lack of research in this field and the ability to provide riders with a scalable home-based training program could be a first step towards answering the question whether fitness interventions can improve riding performance.

\section{Statement of Purpose}

The purpose of this study will be to determine if an 8-week, home-based, isometric strength-training program designed specifically to target riding muscles is a feasible crosstraining intervention for equestrian athletes. A secondary purpose will examine if the 8-week home based intervention affects muscular fitness (strength and endurance) and improve riding test performance. A tertiary purpose will be to explore the relationship between changes in muscular fitness and changes in the riding test performance from baseline to the completion of the 8-week home based, isometric strength training program. Exploratory analysis will also be conducted to investigate the relationship between changes in cardiorespiratory function, body composition and changes in riding performance.

\section{Research Questions}

RQ1: Will an 8-week, home-based isometric strength-training program be a feasible cross-training exercise intervention for equestrians?

RQ2: Will an 8-week, home-based isometric strength-training program improve muscular strength and muscular endurance of the specific muscles associated with postural maintenance during riding? 
RQ3: Will an 8-week, home-based isometric strength-training program improve scores on a USEF Training Level Rider Test in equestrians?

RQ4: Will changes in muscular fitness be associated with changes in riding performance after 8-weeks of an isometric strength-training program?

\section{Hypothesis}

H1: An 8-week, home-based isometric strength-training program will be a feasible cross training exercise intervention for equestrians.

H2: An 8-week, home-based isometric strength-training program will improve muscular fitness of the specific muscles associated with postural maintenance during riding (muscular strength: handgrip, adductor magnus; muscular endurance: rectus abdominis, erector spinae) in equestrians.

H3: An 8-week, home-based isometric strength-training program will improve riding test (USEF Training Level Rider Test) performance in equestrians.

H4: Changes in muscular fitness due to an 8-week, home-based isometric strengthtraining program will be positively correlated to changes in riding test performance (USEF Training Level Rider Test) in equestrians. 


\section{Definition of Terms and Abbreviations}

Feasibility: The degree to which the intervention prescription is correctly followed, adhered to and completed over the course of the exercise intervention, lasting a total of 8 weeks. The intervention will be considered "feasible" if more than $50 \%$ of participants complete at least $75 \%$ of all exercise sessions (adherence) and perform at least 2 sets of each exercise (compliance) during the 8-week intervention. Adherence and compliance measures will be obtained from the participants' exercise logs at the conclusion of the intervention. Criteria for feasibility was set based on $>50 \%$ of participants representing a statistical majority and completion of $75 \%$ of sessions represented approximately 2-3 sessions per week, which aligns with ACSM standard recommendation guidelines for resistance/strength training.

Dressage: A French term meaning "training" that describes a discipline of horseback riding aimed at developing and maximizing the horse's athletic ability and willingness to work while remaining calm, supple and attentive to the rider (“About Dressage", 2014).

United States Equestrian Federation (USEF) Training Level Rider Test (TLRT): This revolutionary test was released in the fall of 2012 and is a standardized, training level riding test created by the United States Equestrian Federation Dressage Committee involving the walk, trot and canter. The purpose of the test is to evaluate the rider's positioning and body mechanics throughout the three gaits of a walk, trot and canter. The test also evaluates the effectiveness of the rider's independent aids in maintaining proper contact and producing proper movement, balance, bend, figures and transitions with the horse while riding. Basic movement requirements are the free walk, medium walk, working trot rising, working canter, 10 and 20 meter circles and 
the halt. The rider is judged and graded on their position, use of aids, horse's response and performance, accuracy of the exercises and harmony between horse and rider. These 5 components are graded on a scale of 0 (not performed)-10(excellent) with decimals allowed, then multiplied by a coefficient of 2 so that the total final score is a portion of 100 . The test is designed to emphasize the rider's control, assess their strengths and weaknesses and in turn, provide feedback to teach riders where they can improve their abilities. Generally, scoring a 60$65 \%$ or higher on a test suggests enough competency to move up to the next level ("Tests", 2014).

Isometric strength training: Strength exercises designed to cause muscular contraction and force production without drastically shortening the muscle fiber and causing changes in a joint angle.

Muscular strength: Force production in the muscle measured in foot-pounds or Newton's using a dynamometer following standard testing guidelines. The muscles that will be analyzed for this study include the shoulder and back muscles activated in an isometric row, the hand muscles used to squeeze/grip, and the hip adductors.

Muscular endurance: The muscle's ability to resist fatigue from multiple, consecutive contractions. The muscles tested for endurance capacity in this study will be the abdominals (partial curl-ups) and the back extensors (isometric chest raise).

\section{Assumptions}

1. All of the participants will follow the pre-test and post-test guidelines. 
2. All of the participants will be honest in answering questions related to medical history and physical activity (including riding activity).

3. Every participant will report their participation in the exercise intervention honestly using the exercise logs.

4. All participants will maintain current/normal lifestyles throughout the 8 week study period with the exception of the exercise intervention prescribed by researchers.

5. All participants will maintain their normal/regular equestrian training programs throughout the 8-week study period.

\section{Limitations}

1. Despite all participants completing the dressage testing on the same day, time of day may impact horses and riders. However, this is a standard design for a typical dressage test.

2. Some participants will travel to the test site so rider and horse fatigue may be a limiting factor on test performance. However, travel time will be relatively short and is a frequent habit of most active riders and horses.

3. Subject's horses ridden during the test may experience different riding dispositions between the pre-test and the post-test.

\section{Delimitations}

1. A relatively small sample size

2. Due to the average age of an equestrian in the United States being 39 ("National Economic Impact", 2005) the sample will consist of adult equestrians (male and females) of ages between 40 and above. 
3. Subjects come from a variety of horse training backgrounds and practices. However, every rider will be required to have a minimum experience of 1 year of dressage riding.

\section{Significance of the Study}

Equestrian literature is scant in analyzing the physiological effects and characteristics of the athletes who participate in this complex and unique sport. It has been suggested that equestrians do not improve aerobic fitness or muscular strength to any great extent via riding, therefore they must cross-train to improve and maintain these capacities (Meyers, 2006). This study will provide needed information regarding the feasibility and efficacy of an isometric strength-training program (that targets the muscles known to be important when riding) on physical fitness and riding performance in equestrians. Therefore, this study is an important step toward a deeper understanding on how participation in a home based isometric strength training designed to target muscles associated with riding, may improve riding performance, in riders who participate in the equestrian modality of dressage. 


\section{CHAPTER TWO: LITERATURE REVIEW}

\section{Overview}

For the purpose of organization, this review of literature is divided into four main sections. The first section describes the sport of horseback riding. The second section will discuss the horse and rider communication, its relationship to dressage riding, and factors influencing rider positioning. The third section addresses the current understanding of physical fitness characteristics of equestrians in relation to muscular fitness and the last section focuses on presenting the current understanding of the physical demands and movement patterns of a rider on horseback.

\section{The Sport of Horseback Riding}

Horseback riding has existed for centuries as a mean of transportation, tool for war, venue for recreation and a business opportunity. The horse industry in the United States, including racing, showing and recreation, generates between $\$ 10-12$ billion each year and over 1.4 million jobs. Showing is the second most popular activity of the three with over 2.7 billion horses involved. Showing may range from rodeo to carriage driving, three-day eventing to halter confirmation ("National Economic Impact", 2005). Although the disciplines are vast and the tasks involved of horse and human are drastically different, there is a paramount common thread across all disciplines: communication. Physical communication between horse and rider/handler is particularly vital to the safety and performance of the pair as one complex coupled system (Peham et al., 2001). One of the most intense depictions of communication between horse and rider is in the discipline of dressage. Dressage, as described by The Federation Equestre 
International, an international governing body for equestrian sports, is both an art and a magic of the highest manifestation of horse training where horses are ridden at all three gaits (walk, trot and canter) to complete memorized tests of patterns and movements ("About Dressage", 2014). Dressage quality is commonly described as harmony between horse and rider, encompassing both the athleticism of the horse and the effortless-appearance of the rider as they work to achieve perfect understanding (Peham et al., 2001). Dressage, as well as other disciplines of riding, requires specific, accurate and effective communication between horse and rider through various physical points of contact such as the legs, seat and hands, collectively referred to as "aids". The correct use of these aids by the rider in requesting particular action of the horse is vital to good performance in both training and competition.

\section{Horse and Rider Communication and Rider Positioning}

Different combinations of speed and direction aids are used to communicate and request particular movement from the horse. These points of communication are reciprocal in that the horse and rider both send and receive feedback that is constantly monitored and adjusted to produce the proper movement (Lagarde et al., 2005). In an inexperienced rider, the use of these aids is likely more visually obvious than in a more experienced rider, such as kicking a horse to go forward rather than applying squeezing pressure with the legs. In dressage riding, the goal of the judged ride is for the horse and rider pair to flawlessly complete the series of movements (specific to the level of test chosen) while appearing completely "effortless", as the communication between the pair is visually absent (Lagarde et al., 2005).

The rider's position can both effect and be affected by the horse's movement. Elite rider's positions are less affected by changes in the horse's movement than are less experienced riders (Peham et al., 2001; Schils et al., 1993). Uncontrolled or incorrect positioning (for 
example, losing balance) or rider inexperience, can prevent or hinder the proper communication between horse and rider. An equestrian's muscular fitness (muscular strength and endurance) is important for not only controlling their own position but also for controlling the horse; resisting a pulling horse, moving a lethargic horse forward or requesting lateral movement. Muscular fitness is also important for the rider to withstand long periods of tonic or quasi-isometric muscle contraction as their position is maintained (Terada 2004; Meyers 2006). The human muscles specific to posture maintenance during riding are the adductor magnus, erector spinae and the rectus abdominis (Terada 2000). Lack of strength in postural muscles can promote rider-position asymmetry. Such unevenness can result in conflict between horse and rider communication, loss of balance and potential injury (Symes, 2009). Ways to improve postural strength in riders has not yet been studied but it is known that riding alone fails to significantly improve muscular strength. However, riders were found to have above average upper body and abdominal strength when compared to non-rider norms (Meyers, 2006). This suggests that strength in these regions of the body could be beneficial to the sport of riding but specific physical fitness characteristics that are successful to riding performance have yet to be determined (Alfredson et al., 1998; Meyers et al., 2000; Meyers 2006; Terada et al., 2004; Westerling 1983). Cross-training targeting the postural muscles specific to riding may be an effective stimulus to strengthening these muscles, improve riding posture and produce better riding performance.

\section{Physical Fitness of the Equestrian Athlete}

Performance indicators of athletes (in other sports) like oxygen consumption, anaerobic fitness, muscular strength and muscular endurance have been minimally studied in the equestrian athlete. Due to the nature of the proposed study, this section will emphasize primarily the conclusions about muscular strength and endurance of the equestrian present in current literature. 
Westerling (1983) completed one of the first studies that included examination of muscular strength in the equestrian athlete. Static muscular strength during knee extension, hip adduction, elbow flexion and handgrip were measured through maximal voluntary isometric contractions in both riders and non-riders. Researchers concluded that neither muscular strength nor endurance was significantly different between riders and non-riders and postulated that rider's static muscular contraction only makes a slight contribution when riding (Westerling, 1983). However, more recent studies contradicted Westerling (1983), suggesting that muscular endurance was extremely important for the rider to be able to sustain tonic contractions during riding, which was theorized to help maintain posture (Terada et al., 2004).

Alfredson et al. (1998) theorized that dressage riding and horse jumping subjected the rider to significant weight bearing stress and impact through the thigh. Alfredson and colleague's study examined muscle strength and bone mass of the thigh in female equestrians using a Biodex isokinetic dynamometer and dual energy X-ray absorptiometer (DXA), respectively. Results suggested an association of high muscular thigh strength, concentrically and eccentrically in the hamstrings and eccentrically in the quadriceps, but non-significant differences in bone mass. It was concluded that horseback riding provided little impact on bone mass in female equestrians but may provide a stimulus for muscular strength (Alfredson et al., 1998).

In both equestrian studies completed by Meyers et al. in 2000 and Meyers in 2006, the Robertson Modified Curl-Up Test (CUT), reverse sit-ups/back extensions and push-ups were used to assess abdominal, back and arm muscular strength and endurance in collegiate female equestrians. Handgrip strength was also examined in both studies using a handgrip dynamometer. When compared to other collegiate level athletes, Meyers and colleague's study concluded that equestrians had lower than normal muscular strength. However, when compared 
to female normatives, equestrian athletes had average and above average mean upper body and abdominal strength. The results of Meyers and colleague's study suggest that equestrianism may improve muscular strength above that of non-athletes but not as much as some other sports of the same competitive level (Meyers et al., 2000).

As a follow-up, Meyers completed a second study in 2006 examining the effects of a 14week equestrian training program. Interestingly, but not surprisingly, the results of the study showed that the riders attained no significant improvement in muscular strength from riding alone. The authors concluded that riders need to supplement in-saddle work with traditional aerobic and strength training regimens in order to optimize physiological performance (Meyers 2006).

One of the most significant challenges in analyzing previous equestrian research is the lack of consistency in testing rider's muscular fitness. Westerling (1983) employed the use of a rig and belted chair, likely conceptually similar to the modern day Biodex isokinetic dynamometer, which was used by Alfredson in 1998 (Westerling 1983; Alfredson et al., 1998). Meyers employed functionality tests (that required no additional equipment) analyzing the number of repetitions over time such as curl up tests, back extensions and push ups to asses muscular endurance. A handgrip dynamometer has been used for analysis of strength (Meyers et al., 2000; Meyers, 2006). With various methods used to determine muscular fitness and few studies conducted to date it is currently impossible to evaluate, objectively, the results of previous research on the effect of horseback riding on muscular fitness. Nevertheless, the current literature in this area has identified major muscles that are activated during horseback riding (Terada 2000) and therefore, the recommended progression in this area of research will be to 
design training regiments for these muscles and examine if, by training these muscles, riding can be improved (Meyers 2006).

\section{Demands and Movement Patterns of the Equestrian}

To date, the only studies that investigated biomechanical demands of the equestrian athlete all used dressage horses and riders. The rider's position in the walk, trot and canter, were evaluated using high-speed video kinematics, electromyography and/or movement patterns (Bystrom et al., 2009; Terada 2000; Terada et al., 2004).

Positional differences of the hip, knee, thigh, lower leg, upper arm and trunk have been compared in novice, intermediate and advanced riders completing the walk, rising trot and sitting trot. The more advanced riders had positions parallel to most riding theory descriptions while less experienced riders did not. The upper bodies of advanced riders were more upright and better match the vertical axis than novice counterparts. These less experienced riders deviated from the vertical by leaning forward in their riding position (Schils et al., 1993). This forward tilt was confirmed in a subsequent study that analyzed trunk and leg angles in the walk, trot and canter (Lovett et al., 2005). When moving through the gaits, the tilt of the upper body also tended to increase. As the rider's trunk angle deviated more from the vertical, greater muscle activity may have been required to maintain position, suggesting a possible increased metabolic cost as the gait advanced (Lovett et al., 2005).

In a study by Terada in 2000 , researchers investigated the differences in posture maintenance and use of appropriate supporting muscles between novice and advanced riders. Novice riders were considered those who had one year or less of riding experience while advanced riders were those who were qualified to compete in national student competitions. Muscular contractions were monitored using electromyography at the rectus abdominis, erector 
spinae and adductor magnus muscles. Accelerometers fitted to the helmets of the riders produced information about the movement of the head in a proximal-distal and cranial-caudal direction. In the advanced rider, the rectus abdominis and the erector spinae muscles elicited more synchronized activity of similar frequency unlike the novice rider where frequencies were mixed. Additionally, the novice rider appeared to use the adductor magnus to compensate for the unbalanced upper body. The results of this compensation in the body was seen also as changes in acceleration in the head. The researcher concluded that the changes in the horse's gait presents varying coordination challenges for the rider, particularly in the maintenance of position. The results indicated that the adductor magnus muscle was not only important for leg aids to the horse but also postural maintenance of the rider. Overall, more experienced riders appeared to be able to maintain their posture and better gauge their movements to stay in "sync" with the horse (Terada 2000) when compared to the novice riders. Isometric contractions of these postural muscles are likely used in attempt to maintain posture, as there is very little change in joint angle.

In another study, Terada and colleagues (2004) analyzed more muscles of the upper body including the back, shoulder, arms and core in advanced riders only. Activation patterns of these muscles throughout the same phase of a trot stride were consistent between riders and could be related to the muscle's function in body control and postural maintenance during riding. Terada and colleagues provided a great foundation for the design of strength and conditioning exercise programs that target muscles determined to be active in the upper body of equestrians during riding. By improving these muscles' overall functional capacities (strength and endurance), this would theoretically give the riders better ability to control posture and potentially ride at a higher level. However, no studies to date have examined this possibility. 
Dis-synchronous or disorganized muscle activation in the rider could produce asymmetrical movements that threaten rider stability or position (Symes et al., 2009). Rider asymmetrical movements can also cause asymmetric loading of the horse (Licka et al., 2004), potentially disrupting harmony between horse and rider. Patterns of displacement in the shoulders and positioning of the thoracic girdle throughout various gaits were examined by Symes and colleagues (2009). During this study, it was observed that during both canter leads, riders rotate their thoracic girdle to the left. However, right and left canter leads produced very different movement patterns in the rider's shoulders. When tracking left, riders had a generally synchronous shoulder movement pattern, very unlike the chaotic pattern observed when tracking right. This distinct axial rotation asymmetry could potentially injure the rider or produce mixed messages towards the horse. Even Grand Prix level riders show forms of asymmetry when riding (Byström et al., 2009). Researchers suggested core stability and flexibility interventions out of the saddle could be beneficial in reducing the movement asymmetry in the saddle (Symes et al., 2009).

Overall, posture appears to improve with experience, yet experience does not guarantee perfect posture or positioning. A variety of muscles have been identified as responsible for maintaining the balance and upper body positioning in the equestrian (Terada 2000; Terada et al., 2004). Quasi-isometric muscular contractions are likely responsible in maintaining riding posture by aligning the body's position over it's center of gravity (Meyers 2006). However, improper engagement of these muscles either in timing or synchronization can create asymmetrical imbalances threatening the posture and/or welfare of the rider (Symes et al., 2009). Although the typical in-saddle training of equestrians may have it's place for teaching the rider how to predict and adjust to the horse's movements, muscular fitness, which could influence the 
capacity of the rider to maintain best possible technique, can only be improved to a certain extent with riding alone (Meyers 2006). A cross-training exercise program focused on improving muscular fitness may help improve postural deficiencies in the equestrian athlete. Once again, more research is needed to confirm or refute this possibility.

\section{Summary}

The limited published literature on equestrians involving muscular fitness assessment suggests that riding alone is not enough to trigger strength gains. For this athletic population, traditional load-bearing exercise appears to be necessary to improve fitness characteristics that may help riders to enhance riding performance and consequently achieve better results in competition. However, more studies are needed to evaluate if, in fact, an exercise training program specifically designed to address the rider's muscular demands during riding are warranted. 


\section{CHAPTER THREE: METHODOLOGY}

\section{Subjects}

Due to a large number of older individuals (ages 40 and above) that participate in riding on a regular basis, and the current lack of specific exercise programs that could potentially assist these older riders with their riding performance, 20 equestrians aged 40 to 70 years old will be recruited from the central N.C. piedmont area to participate in this study. Although to our knowledge, no studies exist examining a cross-training intervention in equestrians, a study by Zion et al. (2003) used a home-based resistance-training intervention with elastic bands for elderly patients ( $>60$ years old) and achieved statistical significance with only 8 subjects. Power for the proposed study was calculated based on the Zion et al. (2003) study due to a similarly aged population and similar exercise intervention mode. With a predicted $10 \%$ performance improvement in upper body strength, mirroring the results of the aforementioned study, the proposed study would achieve a power of .80 with 19 subjects. Therefore, we plan to recruit 20 subjects to ensure power and account for a possible dropout.

Inclusion criteria for participants will include: participants must have a minimum of one year of dressage experience and a minimum of five years of general riding experience (discipline independent), be riding regularly ( $\geq 1$ hour per week), not participating in regular, intense exercise training, and willing to maintain current lifestyle habits. Exclusion for subject participation in the study will be determined by a health screening based on the American College of Sports Medicine (ACSM) 2014 guidelines (Pescatello 2014) that determines contraindications to participation in regular exercise. Subjects will also be excluded if they 
present with any orthopedic condition that precludes participation in any of the proposed study activities (fitness tests, riding tests and exercise intervention).

All subjects will be required to complete a comprehensive medical questionnaire. After evaluating the medical questionnaire and if a physician's approval is deemed necessary to insure that the subject can safely participate in this study, the subject will be asked to bring the physician's clearance documentation prior to starting the study.

\section{Recruitment}

Riders and instructors from local horseback riding interest groups and training facilities will be approached by the primary investigator during training sessions, competitions and group meetings to make them aware of the opportunity to participate in this study. In addition, brochures (see Appendix 3.1) will be distributed and posted at local riding facilities explaining the purpose and methodology of the study and the primary investigator's contact information. After a subject demonstrates interest in participating in this study, the subjects will receive information about pre-assessment guidelines (see Appendix 3.2) and a meeting will be scheduled

to take place during week 0 at the Applied Physiology Lab (APL) in the Department of Exercise and Sport Science at the University of North Carolina at Chapel Hill (Chapel Hill, NC). At this meeting, subjects will review and sign informed consent forms, complete comprehensive medical history questionnaires, the primary investigator will determine the ability of the subject to participate in the study, and if cleared, the subject will complete baseline fitness pre-testing.

\section{Instrumentation}

A Physical Activity Readiness Questionnaire (PAR-Q) (see Appendix 3.3) and a medical history questionnaire (see Appendix 3.4) will be used to determine whether or not approval by physician will be required to take part in the study. The short version of the International 
Physical Activity Questionnaire (IPAQ; see Appendix 3.5) will be used to determine current physical activity participation.

A portable stadiometer (Perspective Enterprises, Portage, MI) will be used to measure height to the nearest $0.5 \mathrm{~cm}$. An electronic scale (Healthometer, Bridgewater, IL) will be used to measure body mass to the nearest $0.1 \mathrm{~kg}$. An air-displacement plethysmograher (BodPod, Life Measurement, Inc., Concord, CA) will be used to assess body density. A Polar telemetry system (Polar Electro Inc., Lake Success, NY) will be used to monitor heart rate. A 12” exercise bench will be used to assess cardiorespiratory function using a YMCA 3-minute Step Test. A portable dynamometer (Lafayette Inst. Co., Lafayette, IN) will be used to assess muscular strength. A United States Equestrian Federation (USEF) Training Level Rider Test (TLRT; see Appendix 3.6) judged by the same USEF Registered (R) level judge will be used to assess rider performance. TheraBand elastic tubing (light intensity: yellow; moderate intensity: red; high intensity: green) (“Exercise Instructions", 2014) and a tennis ball will be used for the exercise training intervention.

\section{Research Design Overview}

In this non-randomized, feasibility study, all subjects will complete two laboratory visits for physical fitness tests, one prior to beginning the study intervention (pre-test) and one after the completion of the 8-week exercise intervention (post-test). Subjects will also complete two farm visits for the assessment of riding performance, one prior to beginning the study intervention (pre-test) and one after the completion of the 8-week exercise intervention (post-test). Both laboratory visits will be conducted in the Applied Physiology Laboratory (APL) in the department of Exercise and Sport Science at UNC-Chapel Hill. Both farm visits will be conducted at Folly Farm in Chapel Hill, NC. The initial physical fitness tests and the riding test 
will be conducted during week 0 of the study (fitness tests will be administered during the weekdays and the riding test will be conducted on one of the weekend days of week 0 ). For the fitness tests, subjects may be pre-tested at different times during the week but all subjects will complete the riding test on the same weekend day by the same judge. Following pre-testing, subjects will complete 8-weeks of a strength training intervention. After 8-weeks of exercise intervention, subjects will undergo post-testing. The post-test will occur during week 9 of the study, following the same format administered during week 0 (fitness testing during the weekdays and the riding test on one day of the weekend). Table1.0 below is a graphic representation of the timeline of study events.

Table 1.0: Timeline of Study Events

\begin{tabular}{|cc|c|c|c|c|c|c|c|c|cc|}
\hline $\begin{array}{c}\text { Weekdays } \\
\text { of } \\
\text { Week 0 }\end{array}$ & $\begin{array}{c}\text { Weekend } \\
\text { of } \\
\text { Week 0 }\end{array}$ & $\begin{array}{c}\text { Week } \\
\mathbf{1}\end{array}$ & $\begin{array}{c}\text { Week } \\
\mathbf{2}\end{array}$ & $\begin{array}{c}\text { Week } \\
\mathbf{3}\end{array}$ & $\begin{array}{c}\text { Week } \\
\mathbf{4}\end{array}$ & $\begin{array}{c}\text { Week } \\
\mathbf{5}\end{array}$ & $\begin{array}{c}\text { Week } \\
\mathbf{6}\end{array}$ & $\begin{array}{c}\text { Week } \\
\mathbf{7}\end{array}$ & $\begin{array}{c}\text { Week } \\
\mathbf{8}\end{array}$ & $\begin{array}{c}\text { Weekdays } \\
\text { of } \\
\text { Week } \mathbf{9}\end{array}$ & $\begin{array}{c}\text { Weekend } \\
\text { of } \\
\text { Week } \mathbf{9}\end{array}$ \\
\hline $\begin{array}{c}\text { Fitness } \\
\text { Pre-Test }\end{array}$ & $\begin{array}{c}\text { Riding } \\
\text { Pre-Test }\end{array}$ & EXI & EXI & EXI & EXI & EXI & EXI & EXI & EXI & $\begin{array}{c}\text { Fitness } \\
\text { Post-Test }\end{array}$ & $\begin{array}{c}\text { Riding } \\
\text { Post-Test }\end{array}$ \\
\hline
\end{tabular}

$\mathrm{EXI}=$ Exercise Intervention

\section{General Procedures}

After subjects have demonstrated interest to participate in this study, subjects will be informed of pre-assessment guidelines to follow in the day(s) prior to physical fitness pre and post-testing and will be scheduled for pretesting (completed during Week 0) at the APL. On the day of fitness pre-testing, subjects will read and sign an informed consent form and be assigned a 4-digit identification code. The primary investigator will then insure the subject adhered to the pre-assessment guidelines using a short questionnaire (see Appendix 3.7). Subjects who fail to comply with pre-assessment guidelines will be rescheduled to the following day. Next, subjects will complete a medical history questionnaire and a PAR-Q to determine whether or not approval by physician will be required to take part in the study. Pending approval by the primary 
investigator, subjects will complete the short version of the IPAQ to determine current physical activity participation. The primary investigator will collect demographic information of each subject including age, race, gender, height and weight. Following demographic data collection, each subject will complete in the following order: one BodPod assessment, a YMCA 3-minute step test, muscular strength and lastly, muscular endurance tests. Descriptions of each assessment are described as follows.

\section{Assessments}

\section{Height and Weight}

Subject's height will be measured without shoes, standing with their back against the stadiometer and looking straight ahead. Weight will be measured without shoes and in minimal clothing using an electronic scale.

\section{Whole body air-displacement plethysmography (BodPod)}

Subjects will have a two-compartment assessment of body density using the BodPod. Subjects will be required to remove all jewelry/accessories from their bodies, dress in tightly fitting clothing such as a swimsuit or spandex and sit inside the egg shaped device. Subjects will be asked to remain still and breathe normally while in the BodPod during the scan, with each scan lasting 3-6 minutes. The device will be calibrated and operated by the same technician for each participant. The Brozek formula $(\mathrm{BF} \%=((4.57 / \rho)-4.142))$ will be used to calculate percent body fat from body density values and an estimated residual volume value from the software will be used for the calculation of body density. 


\section{YMCA Three-minute Step Test}

Subjects will step up and down, one foot after the other (up-up-down-down), on a 12" bench for 3 minutes at a metronome pace of 96 beats per minute. Immediately following the 3 minutes of stepping, subjects will remain standing. After 5 seconds of rest, recovery heart rate will be recorded for one minute.

\section{Isometric Muscular Strength Testing}

Hip Adduction: Subjects will be positioned on their side on a padded table with the top leg strapped into the lever arm with padding placed proximal to the medial condyle of the femur and the hip adducted 30-degrees. Axis of rotation of the dynamometer will be placed in line with the head of the femur. The other leg will be immobilized on the table by securing with straps in accordance with Humac Norm testing protocol. When instructed, subjects will adduct the testing leg against the lever arm as hard as possible for 3-4 seconds. Each leg will be tested 3 times with maximal torque used for analysis. Subject will have left and right hip adductors tested.

Isometric Row: Subjects will be seated upright, secured to a chair with arms bent (90-degree angle) at their sides and hands in a neural (0-degree) grip position holding straps with handles connected to a horizontal lever arm. When instructed, subjects will pull back as hard as possible for 3-4 seconds. Subjects will complete 3 trials and maximal torque generated will be used for analysis.

Handgrip: Subjects will hold the dynamometer in the testing hand in a neutral hand position and the elbow flexed at 90-degrees. The base of the dynamometer should rest on the heel of the palm and the handle in the middle of the four fingers. When instructed, the subject will squeeze the 
dynamometer as hard as possible for approximately 5 seconds without moving any other part of their body. Subjects will complete 3 trials and maximum values will be used for analysis.

\section{Muscular Endurance Testing}

Partial Curl-Up Test: Subjects will lie supine on a mat with the knees bent at a 90-degree angle. Hands will be by the side, palms down and fingertips touching a tape mark. Subjects will curl up enough to slide the hands forward and touch a second piece of tape $10 \mathrm{~cm}$ beyond the first tape, and return to starting position. Subjects will complete as many curl-ups as possible in 1 minute, or until form failure.

Isometric Chest Raise: Subjects will lie prone on a padded surface, keeping the hands at the temples, and will raise the upper body so that the head, arms and chest are not in contact with the surface. The subject will hold this position for as many seconds as possible up until 300 seconds or failure to keep the sternum elevated.

Following the fitness testing, subjects will be randomly assigned a riding test time to be completed at Folly Farm (on the same day as all other subjects) during the weekend of week 0 .

\section{Riding Test}

A covered, standard, 8-letter dressage arena (measuring 20m x 40m) at Folly Farm (Chapel Hill, NC) will be used for testing (see Appendix 3.8). A USEF Licensed Technical Delegate will individually judge riders on a United States Equestrian Federation (USEF) Training Level Rider Test. Riders will be randomly assigned a riding time and informed of their riding time during fitness pretesting at the APL. Before testing, all riders will be required to complete a liability waiver for Folly Farm (see Appendix 3.9) in accordance with the facility's standard of practice. The horses and riders will be allowed to warm-up as desired in locations 
surrounding the testing arena. Riders will report to the testing arena a few minutes before their scheduled test time. Once reported, the judge will use a bell or whistle to signify the rider has a 45 second limit to enter the arena and begin their test. Riders will complete the riding test movements in proper sequence and gait. The judge will score the rider's performance at the conclusion of each test. Each test will be videotaped and be used for reference by a second judge in the event that the primary judge is unable to complete post-testing. Researchers will be given each subject's test in a sealed envelope and will remain blinded to the test results until the conclusion of the study. Subjects will also remain blinded to the results until after the study to prevent the potential influence of score of dressage test on motivation to complete the exercise intervention. Videos will be captured with a digital camera and the footage will be uploaded via SD stick to the PI's personal computer (secured with a password) and labeled with the appropriate subject's 4-digit identification codes.

In the event of an injury during riding testing, immediate first aid care will be provided to the rider/horse and if necessary, emergency responders (paramedic or veterinarian, as appropriate) will be notified immediately in accordance with the facility's standard of practice.

\section{Exercise Training Intervention}

Subjects will be instructed how to complete the specific exercises used for the 8-week strength training intervention as a group, after the completion of the initial Riding Test. All subjects will be provided a detailed, printed handout of exercise descriptions/illustrations for reference and an exercise log to complete each session (see Appendix 3.10, 3.11 respectively). In this $\log$, there will be space for each subject to report the number of reps and sets actually completed, the time it takes to complete each exercise session and whether or not the session was completed alone or in the company of another person. Subjects will also be asked to record the 
number of hours that they rode their horse as part of their regular riding schedule during the 8week intervention. The exercise illustrations in the manual will be obtained from the TheraBand Resistance Band and Tubing Instruction Manual ("Exercise Instructions", 2014). The exercise logs will be collected following the 8-week intervention. Exercises will include an isometric row, trunk curl-ups, trunk twists, back extensions and thigh adduction (all with a resistance band of appropriate intensity) and isometric wall squats with a tennis ball between the knees. The research team will provide the subject with the elastic bands and the tennis ball needed for the exercises. Subjects will have email and phone access to the research team should they have questions or concerns about the exercises during the 8-week intervention. Also, the research team will contact subjects one time per week during the 8-week training via phone and/or email to check if the subjects are having any trouble with the exercise program, to encourage continued effort, and to answer any questions about the training regimen. Subjects will be instructed to complete the exercises 3 times a week for the duration of the study intervention. To allow for proper adaptation to the exercise-training program and to stimulate a training response, the progression of training including volume and intensity following the ACSM guidelines is described in Table 2.0 below. 
Table 2.0: Progression of Strength Training Over the 8-week Intervention.

\begin{tabular}{|c|c|c|c|c|c|c|c|c|}
\hline & $\begin{array}{c}\text { Week } \\
\mathbf{1}\end{array}$ & $\begin{array}{c}\text { Week } \\
\mathbf{2}\end{array}$ & $\begin{array}{c}\text { Week } \\
\mathbf{3}\end{array}$ & $\begin{array}{c}\text { Week } \\
\mathbf{4}\end{array}$ & $\begin{array}{c}\text { Week } \\
\mathbf{5}\end{array}$ & $\begin{array}{c}\text { Week } \\
\mathbf{6}\end{array}$ & $\begin{array}{c}\text { Week } \\
\mathbf{7}\end{array}$ & $\begin{array}{c}\text { Week } \\
\mathbf{8}\end{array}$ \\
\hline \# sets/exercise & 2 & 2 & 3 & 2 & 3 & 4 & 4 & 4 \\
\hline \# reps/exercise & 12 & 15 & $10-12$ & 10 & $12-15$ & $10-12$ & $8-10$ & $8-10$ \\
\hline $\begin{array}{c}\text { Intensity/ } \\
\text { Resistance }\end{array}$ & Light & $\begin{array}{c}\text { Light/ } \\
\text { Moderate }\end{array}$ & Moderate & High & Moderate & High & High & High \\
\hline $\begin{array}{c}\text { Rest } \\
\text { (between sets) }\end{array}$ & $\begin{array}{c}45 \mathrm{~s}-1 \\
\text { min }\end{array}$ & $45 \mathrm{~s}$ & $30-45 \mathrm{~s}$ & $30-45 \mathrm{~s}$ & 1 min & $\begin{array}{c}1-1.5 \\
\min \end{array}$ & $\begin{array}{c}1-1.5 \\
\min \end{array}$ & $\begin{array}{c}1-1.5 \\
\mathrm{~min}\end{array}$ \\
\hline $\begin{array}{c}\text { Isometric } \\
\text { Holds }\end{array}$ & $20-30 \mathrm{~s}$ & $30-40 \mathrm{~s}$ & $40 \mathrm{~s}$ & $45-50 \mathrm{~s}$ & $40 \mathrm{~s}$ & $45-50 \mathrm{~s}$ & $50-55 \mathrm{~s}$ & $\begin{array}{c}55 \mathrm{~s}- \\
1 \mathrm{~min}\end{array}$ \\
\hline
\end{tabular}

Intensity represents the color of the theraband. Each color represents a different level of resistance;

Yellow $=$ Light resistance, Red $=$ Moderate resistance; Green $=$ High resistance.

Before beginning each exercise training session, subjects will be asked to walk, bike or use an elliptical machine if available for approximately 6 minutes as part of an initial warm-up. After the 6 minutes, they will perform overall body stretching (see Appendix 3.13) then begin the exercise intervention training session. Subjects will be advised and encouraged to breathe well through the exercises to prevent a Valsalva maneuver. The specific intervention exercises should be completed as follows:

Trunk Curl-Ups: Subject should attach elastic to a non-moveable object near the floor behind their head, lie on their back with bent knees, grasp the elastic with straight arms and both hands overhead, slowly curl trunk upward bringing the shoulder blades off the floor then return to starting position and repeat.

Trunk Twists: Subject should attach elastic to a non-moveable object from the side at waist height, be seated and grasp the elastic with both hands at the navel, twist away from the elastic to the side then return to the starting position and repeat. 
Back Extensions: Subject should attach elastic to a non-moveable object at shoulder height, be seated and grasp the elastic with both hands at their chest, pull backwards straightening the truck then slowly return to starting position and repeat.

Isometric Seated Row: Subject should attach elastic to non-moveable object, hold elastic in their hands, sit upright keeping bent elbows near their sides and squeeze shoulder blades together while pulling the resistance band and hold the position.

Hip Adduction: Subjects should attach the elastic to a non-moveable object at ankle level at their side, place the foot that is on the same side of elastic in the elastic loop, keep their knee straight, pull the leg inward and hold the position.

Wall Squats: Participants should put their back on a wall, squat down with knees bent at a 90-degree angle, place a tennis ball between the knees and maintain weight in the heels. Elbows or hands should not come in contact with the thighs and squatted position should be maintained.

Following the 8-weeks of strength training intervention and all post-testing, subjects will be asked via questionnaire (see Appendix 3.14) whether or not they enjoyed the prescribed intervention and if they plan to continue the intervention or a similar cross-training strategy in the future as a way to improve their riding performance.

\section{Statistical Analysis and Design}

Descriptive statistics, including means and standard deviations will be calculated for demographic data, fitness variables and riding performance scores. All data will be analyzed using SPSS Version 20.0 (Chicago, IL). Statistical significance will be set a priori at an alpha level of $\leq .05$. Power analysis was not calculated for this study due to its novelty and lack of data regarding the intervention and population that will be used in this study. The results of this study 
will hopefully serve as reference for calculations of power to in the development of future interventions using similar protocols.

H1: An 8-week, home-based isometric strength-training program will be a feasible cross training exercise intervention for equestrians. Feasibility will be determined by calculating average adherence and compliance of the subjects to the exercise intervention by using data from the participant's exercise logs. The intervention will be considered feasible if more than $50 \%$ of the participants complete at least $75 \%$ of the 24 sessions performing at least 2 sets of each exercise and at least half of the prescribed number of repetitions at the prescribed intensity.

H2: An 8-week, home-based isometric strength-training program will improve muscular fitness (strength and endurance) from pre-test to post-test at the end of the 8-week training program. Hypothesis 2 will be analyzed using 2 dependent samples t-tests. The first dependent sample ttest will compare the results of muscular strength from pre-test to post-test. A composite score consisting of the addition of the results of the handgrip, hip adduction and isometric row strength tests will be used for the analyses. The second dependent samples t-test will compare the results of the pre-test to post-test muscular endurance tests. A composite score consisting of the addition of the results from the partial curl-up and back extension tests will be used for the analyses.

H3: An 8-week, home-based isometric strength-training program will improve total riding test (USEF Training Level Rider Test) performance in equestrians. Hypothesis 3 will be analyzed using a dependent samples t-test using the pre and post-test total score from the USEF Rider Test. 
H4: Changes in muscular fitness (strength and endurance) due to an 8-week, home-based isometric strength-training program will be positively correlated to changes in riding test performance (USEF Training Level Rider Test) in equestrians. Hypothesis 4 will be analyzed using two simple regression models; the first simple regression will be used to evaluate the correlation between muscular strength (Independent variable) and total riding performance score (Dependent variable). Changes (Delta scores $=$ post-test - pre-test of the composite variable created for muscular strength consisting of the addition of the results of the handgrip, hip adduction and isometric row strength tests) and the changes in the results of the scores of the riding test (delta scores $=$ post riding test - pre riding test score, dependent variable) will be used for the correlation analysis. The second simple regression will evaluate the correlation between muscular endurance (Independent variable) and riding performance score (Dependent variable). Changes $($ delta scores $=$ post-test - pre-test of the composite variable created for muscular endurance consisting of the addition of the results of the partial curl-up and back extension tests) and the changes in the results of the scores of the riding test (delta scores $=$ post riding test - pre riding test score, dependent variable) will be used for the correlation analysis.

Exploratory analysis will examine the relationship between changes (delta scores) in cardiorespiratory fitness and body composition from pre-exercise intervention to post-exercise intervention (dependent variables) with changes (delta scores) in riding performance, calculated from the results of the USEF Riding Test (independent variable). 


\section{CHAPTER FOUR: RESULTS}

\section{Overview}

The primary purpose of this study was to determine the feasibility of an 8-week, homebased, isometric strength-training program designed specifically to target riding muscles as a cross-training intervention for equestrian athletes. A secondary purpose was to examine if the 8week home based intervention affected muscular fitness (strength and endurance) and improved riding test performance. A tertiary purpose was to explore the relationship between changes in muscular fitness and changes in the riding test performance from baseline to the completion of the 8-week home based, isometric strength training program. Exploratory analyses were also conducted to investigate the relationship between changes in cardiorespiratory function, body composition, riding test component scores and overall riding performance test scores. All data were entered into an electronic database and analyzed using the statistical software SPSS, version 19 for Mac. Alpha level was set a priori at 0.05 for all analyses. Descriptive statistics are presented in the form of means and standard deviations. When performing multiple paired samples t-tests, a Bonferroni adjustment was implemented to minimize the likelihood of a Type I error.

\section{Subjects}

Twenty subjects total were recruited and 18 subjects completed the entire study. One participant was unable to complete the study after diagnosis of a non-study related neurologic condition and the other subject did not comply with the study intervention. Therefore, 18 
subjects were included in the analyses. Physical characteristics of the subjects and amount of hours of riding per week are presented in Table 3.

Table 3.0: Rider Physical Characteristics (mean \pm SD)

\begin{tabular}{|c|c|c|}
\hline Characteristic & Pre-Intervention & Post-Intervention \\
\hline Age (years) & $54.1 \pm 7.7$ & - \\
\hline Height (cm) & $165.8 \pm 5.7$ & $165.8 \pm 5.7$ \\
\hline Weight (kg) & $68.6 \pm 12.2$ & $68.7 \pm 12.3$ \\
\hline Fat Mass (\%) & $29.6 \pm 6.7$ & $29.9 \pm 7.1$ \\
\hline Fat Free Mass (\%) & $70.4 \pm 6.7$ & $70.1 \pm 7.1$ \\
\hline Hours of Riding Per Week & $\begin{array}{c}\text { Minimum of 1 hour } \\
\text { required }\end{array}$ & $4.1 \pm 2.2$ \\
\hline
\end{tabular}

Study participants completed an average of $19 \pm 4.4$ of 24 prescribed exercise sessions ( $\sim 80 \%$ of total sessions) and rode their horse(s) for approximately $4 \pm 2.2$ hours per week. The results of the physical fitness and riding tests pre and post intervention are presented in Table 4. 
Table 4.0: Physical Fitness and Riding Test Performance Scores (mean $\pm \mathrm{SD}$ )

\begin{tabular}{|c|c|c|}
\hline Test & $\begin{array}{l}\text { Pre-Intervention } \\
\quad(\mathrm{N}=18)\end{array}$ & $\begin{array}{l}\text { Post-Intervention } \\
\qquad(\mathrm{N}=18)\end{array}$ \\
\hline $\begin{array}{l}\text { Step Test Recovery } \\
\text { Heart Rate (bpm) }\end{array}$ & $97.7 \pm 18.9$ & $93.4 \pm 17.3^{*}$ \\
\hline Isometric Row (ftlb.) & $19.2 \pm 4.4$ & $27.6 \pm 5.1^{*}$ \\
\hline $\begin{array}{l}\text { Right Hip Adduction } \\
\text { (ftlb.) }\end{array}$ & $35.8 \pm 10.9$ & $57.6 \pm 19.1^{*}$ \\
\hline Left Hip Adduction (ftlb.) & $36.1 \pm 9.1$ & $52.7 \pm 16.5^{*}$ \\
\hline Hip Adduction Total & $71.9 \pm 19.1$ & $110.3 \pm 33.0^{*}$ \\
\hline Right Handgrip (lb.) & $31.4 \pm 4.9$ & $32.7 \pm 4.8^{*}$ \\
\hline Left Handgrip (lb.) & $30.4 \pm 6.0$ & $30.5 \pm 5.5$ \\
\hline Handgrip Total (lb.) & $61.8 \pm 10.5$ & $63.2 \pm 10.1^{*}$ \\
\hline $\begin{array}{c}\text { Composite Muscular } \\
\text { Strength }^{\infty}\end{array}$ & $152.8 \pm 29.5$ & $201.1 \pm 43.5^{*}$ \\
\hline Partial Curl Up (reps) & $38.1 \pm 13.9$ & $45.9 \pm 12.5^{*}$ \\
\hline $\begin{array}{l}\text { Isometric Chest Raise } \\
(\mathrm{sec})\end{array}$ & $111.7 \pm 73.4$ & $163.3 \pm 105.5^{*}$ \\
\hline $\begin{array}{c}\text { Composite Muscular } \\
\text { Endurance }^{\wedge}\end{array}$ & $149.8 \pm 82.2$ & $209.2 \pm 112.3^{*}$ \\
\hline $\begin{array}{l}\text { USEF Training Level } \\
\text { Rider Test Total Score } \\
(\# / 100)\end{array}$ & $57.9 \pm 7.4$ & $60.9 \pm 5.1^{*}$ \\
\hline $\begin{array}{l}\text { Rider Position Component } \\
\text { Score }(\# / 20)\end{array}$ & $11.2 \pm 1.9$ & $11.9 \pm 1.4$ \\
\hline $\begin{array}{l}\text { Effective Use of Aids } \\
\text { Component Score }(\# / 20)\end{array}$ & $11.4 \pm 1.7$ & $11.9 \pm 1.0$ \\
\hline
\end{tabular}

$*<.05=$ significant different from pre-intervention

$\infty$ Composite Muscular Strength: sum of isometric row, total hip adduction and handgrip total scores

$\wedge$ Composite Muscular Endurance: sum of partial curl up and isometric chest raise scores

Component Scores are 5 categories each worth 20 points, which collectively contribute to the total riding test score. Rider Position component evaluates the rider's symmetry and alignment in the saddle. Effective Use of Aids component evaluates performance as a result of proper communication between horse and rider.

\section{Hypotheses}

Hypothesis 1, an 8-week, home-based isometric strength-training program will be a feasible cross training exercise intervention for equestrians, was determined by calculating the 
subject's average adherence and compliance with the exercise intervention by using data from the participant's exercise logs. The intervention was considered feasible as more than half of the participants ( 11 out of 18 of the subjects) completed $75 \%$ of the 24 sessions performing at least 2 sets of each exercise and at least half of the prescribed number of repetitions at the prescribed intensity.

Hypothesis 2, an 8-week, home-based isometric strength-training program will improve muscular fitness (strength and endurance) from pre-test to post-test at the end of the 8-week training program was analyzed using dependent samples t-tests. Composite scores consisting of the addition of the results of the handgrip, hip adduction and isometric row strength tests assessed pre and post the exercise intervention were used for the analyses of muscular strength. Significant improvements in muscular strength from pre to post intervention $(\mathrm{p}<.005)$ were observed. Composite scores consisting of the addition of the results from the partial curl-up and back extension tests assessed pre and post the exercise intervention were used for the analyses. Significant improvements in muscular endurance from pre to post intervention were observed $(\mathrm{p}=.001)$.

Hypothesis 3, an 8-week, home-based isometric strength-training program will improve total riding test (USEF Training Level Rider Test) performance in equestrians, was analyzed using a dependent samples t-test using pre and post total scores from the USEF Training Level Rider Test. Significant improvements were observed from pre to post intervention in the Rider Test total scores $(\mathrm{p}=.037)$.

Hypothesis 4, changes in muscular fitness (strength and endurance) due to an 8-week, home-based isometric strength-training program will be positively correlated with changes in riding test performance (USEF Training Level Rider Test) in equestrians, was analyzed using 
simple regression models. The first simple regression evaluated the correlation between muscular strength (independent variable) and total riding test performance score (dependent variable).

Changes in muscular strength (delta scores= post-test - pre-test of the composite variable created for muscular strength consisting of the addition of the handgrip, hip adduction and isometric row strength test values) and the changes in the results of the total scores of the riding test (delta scores $=$ post total riding test performance score - pre total riding test performance score, dependent variable) were used for the correlation analysis. No significant correlations were found between changes in muscular strength and changes in total riding test performance score $\left(\mathrm{r}^{2}=.104, \mathrm{p}=.096\right)$. The second simple regression evaluated the correlation between muscular endurance (independent variable) and total riding test performance score (dependent variable). Changes (delta scores $=$ post-test - pre-test of the composite variable created for muscular endurance consisting of the addition of the partial curl-up and back extension test values) and the changes in the results of the total riding test performance scores (delta scores $=$ post total riding test performance score - pre total riding test performance score) were used for the correlation analysis. A significant correlation was found between changes in muscular endurance and changes in total riding test score $\left(\mathrm{r}^{2}=.285, \mathrm{p}=.011\right)$, with muscular endurance accounting for almost $30 \%$ of changes in total riding test performance scores.

\section{Exploratory Analyses}

Exploratory analyses examined the relationship between changes in muscular fitness and changes in USEF Training Level Rider Test riding test component scores. The first variables analyzed were changes in muscular endurance composite score (dependent variable) and changes in the Rider's Effective Use of Aids score from USEF Training Level Rider Test (independent variable). A significant correlation was found between changes in muscular endurance and 
changes in the Rider's Effective Use of Aids score $\left(r^{2}=.244, p=.019\right)$ with muscular endurance accounting for $24 \%$ of the changes in the Rider's Effective Use of Aids score. Conversely, there was no correlation found between changes in muscular endurance and changes in Rider's Position score $\left(\mathrm{r}^{2}=.071, \mathrm{p}=.285\right)$. The influence of changes in muscular strength composite score on changes in the USEF Training Level Rider Test component scores was also evaluated. No significant correlations were found between changes in muscular strength and changes in the Rider's Effective Use of Aids score $\left(\mathrm{r}^{2}=.054, \mathrm{p}=.351\right)$. The relationship between changes in muscular strength and changes in Rider's Position score, however, did approach significance $\left(\mathrm{r}^{2}=.171, \mathrm{p}=.08\right)$ with changes in muscular strength likely accounting for $\% 17$ of changes in Rider's Position score.

The relationship between changes in riding test component scores (which collectively produce the total USEF Training Level Rider Test score) and changes in total riding test scores from pre to post intervention were evaluated to determine the potential influence of each component on the overall test score. The components analyzed were Rider Position score and Rider's Effective Use of Aids score. A significant correlation was observed between changes in Rider Position score and changes in total riding test scores $\left(\mathrm{r}^{2}=.772, \mathrm{p}<.005\right)$ with changes in Rider Position score accounting for $77 \%$ of changes in the total riding test performance score. Additionally, a significant correlation was observed between changes in Rider's Effective Use of Aids score and changes in total riding test performance score $\left(\mathrm{r}^{2}=.636, \mathrm{p}<.005\right)$, with Effective Use of Aids score accounting for $63 \%$ of changes in the overall riding test score.

Exploratory analyses using simple regression models were conducted to examine the relationship between variables that could assist in understanding the effects of the intervention on riding performance. The first exploratory analysis, examining the relationship between hours 
of riding per week and changes in total riding test performance scores, was performed using each subject's average hours of riding per week (dependent variable) as reported in their exercise logs and delta scores calculated from the results of the USEF Training Level Rider Test total score (independent variable). No significant correlation was found between average hours of riding per week and changes in total riding test performance scores $\left(r^{2}=.003 ; p=.418\right)$.

The relationship between changes in cardiorespiratory fitness (dependent variable) and changes in total riding test performance scores (independent variable) from pre to post-exercise intervention was also evaluated. No significant relationship was found between cardiorespiratory fitness and changes in riding test performance $\left(r^{2}=.004, p=.404\right)$. 


\section{CHAPTER FIVE: DISCUSSION AND CONCLUSION}

\section{Overview}

The purpose of this study was to determine if an 8-week, home-based, isometric strengthtraining program designed specifically to target riding muscles would be a feasible cross-training intervention for amateur equestrian athletes. Further investigations examined the effect of the intervention on muscular fitness (strength and endurance) and riding test performance as well as the relationship between changes in different components of fitness (i.e. cardiorespiratory function, muscular fitness, and body composition) and changes in the riding test performance from baseline to the completion of the intervention. Deeming that the exercise intervention used in this current study was feasible and promoted positive changes in different component of fitness of the riders, another goal of current study was to provide insight to the specific physical fitness characteristics of riders that may influence riding performance, which other studies had yet to determine (Alfredson et al., 1998; Meyers et al., 2000; Meyers 2006; Terada et al., 2004; Westerling 1983).

Muscles pertinent to posture maintenance during riding have been identified and knowledge that lack of strength in those muscles promotes rider-position asymmetry exists (Terada 2000; Symes 2009). Furthermore, a previous study by Meyers et al. (2006) concluded that in-saddle only practice was not sufficient enough to promote significant improvements in rider muscular fitness (Meyers 2006). Some of the same muscles examined in Meyers et al. (2006) study were targeted for the strength training intervention, and fitness testing in the current study. To our knowledge, never before has an out-of-the-saddle cross training intervention 
specifically created to improve in-the-saddle performances been designed and implemented, until the current study.

It is important to note that the current study was only powered for feasibility and muscular fitness changes. The study was not powered for correlation calculations and all correlation implications should be considered strictly exploratory. A future study of increased sample size and with a control group is necessary to confirm or refute the results of the analyses implemented in the current study.

\section{Feasibility}

Due to the conclusions from the few studies existing that examined some aspects of rider fitness (Alfredson et al., 1998; Meyers et al., 2000; Meyers 2006; Terada et al., 2004; Westerling 1983) but had not examined the effects of exercise training on riders performance, it was imperative to first determine the feasibility of an exercise program. Determining whether or not a group of equestrians would complete a cross training intervention at all is important for the design of future programs. It is well understood that the sport of riding is a time consuming endeavor, thus a home-based program using only resistance bands and body weight was designed to maximize the opportunity for ease and versatility.

Based on the subject's responses of adherence and compliance to the prescribed program, collected from the self-report exercise logs, the current intervention was deemed feasible and promoted positive training responses. Participants completed an average of 2-3 sessions per week and targeted most major muscle groups. An exit questionnaire also revealed the study was well liked by the majority of the participants. Subjects reported feeling much more aware of their posture both in and out of the saddle, and were confident they could tell a true difference in 
themselves as the intervention progressed. Two subjects independently reported, on behalf of their trainers, that the trainers stated to have observed significant in-saddle improvements while the rider was participating in the study. Subjects seemed to most appreciate the versatility of the bands as it allowed them to complete the exercises almost anywhere and the time commitment per session was reasonable for their schedules. One participant traveled overseas and was still able to complete the exercises because the bands packed well into luggage. Conversely, many of the riders agreed they least liked the wall squat exercise, as it was the most challenging. Some riders felt there was a discrepancy in the difficulty between the different exercises but supported that each exercise was specific to riding. Subjective responses are of utmost importance when analyzing an intervention due to the practical understanding that a program that is generally enjoyed likely improves the chances of subject adherence.

\section{Muscular Fitness}

The strength training intervention using resistance bands in this study produced significant changes in the rider's muscular strength and muscular endurance. These improvements in muscular fitness align with the results found in a previous study examining the effect of strength training using Therabands in 20 women aged 50 years and older completing an intervention of very similar design (Delshad et al., 2013). In the current study, the fitness testing and strength training intervention was specifically designed to target the muscles previously determined to be pertinent to posture maintenance for riding: the adductor magnus, erector spinae and the rectus abdominis (Terada 2000). Previous research has used inconsistent techniques to determine the fitness of the muscles identified and of riders in general. The ability to compare performance scores using identical tests is essential to expand the pool of knowledge 
regarding a population, and the demands to study equestrians are no exception. The current study therefore used a variety of tests previously implemented by researchers to evaluate the subjects in the current study, specifically the partial curl up, handgrip and back extension tests (Meyers et al., 2000; Meyers, 2006). Likely similar to the apparatus described in previous studies, the current study also implemented the use of an isokinetic dynamometer to assess hip adduction and upper body strength (Westerling 1983; Alfredson et al., 1998). Every muscular fitness test used to assess changes from pre to post intervention targeted riding specific muscles.

The strength training intervention exercises were explicitly designed to progressively train the riding specific muscles in order to maximize adaptation in congruence with standard principles of training. The training intervention was isometric in nature to reflect the isometric demands of muscles experienced while riding. Equestrians rely on isometric muscular contractions while riding to stabilize the body, maintain position, and signal/communicate with the horse (Meyers 2006). Because these contractions are held for extended periods of time while in the saddle, increasing the endurance rather than strength of these muscles was of primary importance when designing the intervention. The intervention progressively challenged the riding-specific muscles to develop tension at increasing workloads due to the 3 different band intensities. The muscles remain contracted at the various workloads for longer periods of time as the 8-weeks progressed. In doing so, the muscle is forced to adapt and improve energy systems necessary to fuel the contractions. Due to the short intervention time of this program, the improvements in muscular fitness, specifically strength, are likely neural in origin, however, some biochemical improvements may be present within this short time (Moritani and deVries, 1979). The muscles activated in the intervention are predominantly reliant upon phosphocreatine and glycolytic systems that use ATP stored directly in the muscle. However, accumulation of 
fatigue-inducing bi-products such as hydrogen ions and a concurrent decrease in $\mathrm{pH}$ in the active muscle will eventually lead to failure to maintain contraction. With proper training, the muscles become more reliant upon oxidative energy sources (Kiens et al., 1992). Thus, training allows a shift to oxidative substrate usage, a delay in the onset of metabolite accumulation associated with fatigue, and an overall increased efficiency, which improves muscular endurance.

The use of the resistance bands provided a simple yet appropriate and effective intervention strategy for the particular population, especially with respect to time as the homebased design did not require travel to/from a gym facility. The bands also did not require significant space, were easy to move, store, and were quiet to use. Although only 3 intensities were used for this intervention, a variety of progressing intensity bands are available so riders have the ability to advance. Weeks 1-3 of the training protocol gradually increased in volume and intensity, followed by a slight decrease during week 4 to allow for recovery, and finished with further increases in volume and intensity from weeks 5-8.

The potential for improvements in fitness testing due solely to subject's learning was possible, as with many testing protocols. However, the magnitude of change in many of the tests suggests actual physiologic improvements due to the training intervention. A previous study also using an elastic band strength training intervention of similar duration and progression in a similarly aged, all-female population found significant improvements in muscular fitness (Colado et al., 2012). A review and meta analysis on strength training using elastic bands also concluded the mode as an effective way to improve strength, particularly in elderly populations (Martins et al., 2012). Based on the results of this study and previous literature, it is reasonable to conclude that the performance improvements are likely due to the cross training intervention. 


\section{Riding Test}

Unlike the findings of a previous study on the effects of in-saddle only training on muscular strength, the current study found improved muscular strength performances from pre to post intervention (Meyers 2006). However, exploratory analyses revealed there was no significant correlation between changes in muscular strength and changes in total riding test performance score or Rider's Effective Use of Aids score. Correlations between changes in muscular strength and changes in Rider Position scores approached significance. Although it is obvious that some amount of strength is required to ride and work with horses, the ability to generate a high force contraction to be used as an aid while riding would likely be short-lived and not particularly beneficial. Communication with the horse while riding relies on continuous, maintained aids (popularly referred to as a "connection") from substantial but not overly powerful muscular contractions. This "connection" between horse and rider is far more reflective of muscular endurance than muscular strength. As predicted, muscular endurance was found to significantly positively correlate not only with changes in the Rider's Effective Use of Aids score but also total riding test performance score. Furthermore, and perhaps less surprisingly, changes in the Rider's Effective Use of Aids score significantly correlated with changes in total riding test performance score. These results yield logical conclusions, especially to a seasoned rider, and will be elaborated upon momentarily. In relation to rider position, previous literature has speculated that position is maintained using long periods of tonic or quasi-isometric muscle contractions, and thus the ability to endure these contractions suggests an enhanced potential to maintain better posture (Meyers 2006; Terada et al., 2004). However, surprisingly, muscular endurance and Rider Position scores were not significantly associated in the current study. It is possible that because the riders in this study were amateurs, yet, moderately experienced, their 
position is established and sufficient to perform at the level required by the Training Level Rider Test. Therefore, positional changes may not be drastically impacted by changes in muscular endurance. Previous studies support this notion that as experience level increases, instability insaddle appears to decrease and approximation of the ideal riding position becomes more obvious (Terada 2000; Peham et al. 2001; Schils et al. 1993). Additionally, it has been found that differences in the kinematic variables governing position are smaller when the rider is more experienced (Schils et al 1993).

Aids however, unlike position, are used to request the horse's movement and are generally only as effective as long as the aid can be given correctly and maintained. As dressage riding level progresses, the level of difficulty of movements required increase as well. At higher performance levels, movements are executed for longer periods of time with more step, direction, and gait changes. More effective aids, therefore, should result in better production of the intended movement and thus, ideally, an improvement in overall performance. Thus, there is a rational connection between improvements in muscular endurance, and effectiveness of aids in relation to overall performance. Especially in a well-trained mount, a horse should respond to an aid as long as the aid is given. If the strength of the aid cannot be maintained and the aid diminishes, the horse's reaction is likely to diminish as well, negatively impacting performance. Based on the results of the current study, when considering the riders as moderately trained, it appears that improvements in muscular endurance may impact the riders use of their bodies more than the position of the body itself with regards to overall performance. Interestingly, the correlations between changes in component scores and changes in overall test scores suggest overlap between Rider Position and Effectiveness of Aids with regards to their impact on overall performance. With changes in Rider Position accounting for approximately $77 \%$ of changes in 
overall performance, and Rider's Use of Aids score accounting for approximately $63 \%$ of changes in overall performance, the notion that position and aids are related is likely. As before, this potential association is sensible to a seasoned rider as the proper position of the body is important for requesting the proper aid. As an elementary example, a young child learning to ride may cause a horse to unexpectedly speed up instead of halt because they are leaning forward rather than pulling on the reins and staying upright. Again, the current study was not powered to complete correlations and the notions presented here are purely speculative.

Muscular endurance sensibly relates to a rider's ability to engage with the horse, but it may also have implications for safety. Muscular fatigue has been directly linked with the increased likelihood of sustaining injury (Rohmert 1973). The potential for injury due to fatigue, when considering a rider atop a horse, is particularly concerning. Therefore, improvements in muscular endurance may be warranted not only to potentially improve attentive riding performance but to also prevent potential fatigue-induced injuries.

One of the greatest challenges when studying the horse/rider pair is controlling the horse as a variable. In the current study, in order to help identify potentially detrimental horse temperament during testing, the riders and judge scored the horses on a 1-3 temperament scale after each ride for both pre and post testing. On average for both test sessions, the riders and judge agreed the horses performed "normally". The performance improvements in the riding tests were appropriate based on the characteristics of the intervention, and reasonable for the time of in-saddle training that could take place from beginning to end of the study. Based on the average score for the first dressage test $(\bar{x}=57.9)$ and the ability to complete all of the movements and gaits required for the Training Level Test, the riders in this study were already moderately experienced. Riders obviously had a decent grasp of the skills needed to successfully 
complete the riding test, which included movements at a walk, trot and canter, directional changes and geometrical patterns. The score for the post-test improved by 3 points $(\bar{x}=60.9)$. Without a control group, it is difficult to conclude whether or not the improvements were purely due to the training intervention. However, subjects were asked to maintain all other in and outof-saddle training habits during the eight weeks so the only significant difference in training from pre to post testing should be the strength training intervention. With a post-score of 60.9, riders crossed the threshold score of 60 , which has been loosely regarded as a score that represents when the horse/rider pair are ready to advance to the next level (http://www.equineworld.co.uk/horse_sports/dressage_scoring.asp). In relation to the current study, a simple 8week strength training intervention may provide the stimulus necessary to transition riders to the next competitive level.

\section{Exploratory Analyses}

Cardiorespiratory fitness of the equestrians was examined (using the YMCA Step Test) primarily to better characterize the athletes and contribute to the growing pool of information describing equestrians. Previous research suggests that equitation training alone does not improve cardiorespiratory fitness and cross training would likely be required to elicit changes (Meyers 2006). The strength training intervention in the current study was not intentionally designed to improve cardiorespiratory fitness in the equestrians. However, the recovery heart rates from the step test significantly decreased from pre to post intervention $(\Delta=-4.3 \pm 7.6 \mathrm{bpm})$. The riders relied substantially on the strength of their quadriceps muscles, and their overall balance, to complete the test. Further introspection as to why the cardiorespiratory changes may have occurred resulted in the recognition that one of the intervention exercises, the wall squat 
with tennis ball between the knees, may have elicited enough training stimulus to produce significant improvements in quadriceps strength. The wall squat, although a great exercise for quad strength, included squeezing a tennis ball between the knees and was thus originally implemented to target the adductors, core and back muscles. Additionally, the core strengthening exercises may have contributed to better upper body control and therefore balance. The study population was essentially untrained outside of riding conditioning and therefore the wall squat may have been a strong enough stimulus to improve not only muscular strength and endurance but cardiorespiratory fitness as well. With improved quad strength and balance from pre to post testing, the step test may not have been as challenging of a task, potentially allowing the riders to more efficiently perform the test. This may have resulted in the decreased recovery heart rate values seen in post testing. Interestingly, most subjects reported to dislike the wall squat exercise, frequently referring to it as the most challenging of the 6 exercises. Regardless, safe improvements in cardiorespiratory fitness, especially in a population of this age should be welcomed and encouraged. Further research is needed to confirm what stimulus may have produced the improvement in cardiorespiratory fitness in the current study.

The body composition assessment, like the cardiorespiratory testing, was implemented to help better characterize the population. Unlike the recovery heart rates, body composition was not significantly altered from pre to post intervention, as expected, as the stimulus was not appropriate to elicit those changes. It is important to recognize that the mean body fat percentage of the group was almost $30 \%$, which has dangerous health implications. These results were even greater than values reported in previous research with body fat percentiles of equestrians ranging from 23-28\% (Alfredson et al. 1998; Meyers 2006; Meyers et al., 2000; Roberts et al., 2009). Robertson et al. (2009) pointed out the higher body fat levels of equestrians suggests poor 
physical conditioning in relation to other groups of athletes. This should be an important factor to consider and target for improvement when training future populations of equestrians. Previous research has concluded that in-saddle only training also failed to improve body composition, therefore, greater physical activity and diet alterations are likely necessary to produce significant body composition changes in this population (Meyers 2006).

\section{Conclusion}

Although this study, primarily a feasibility study, had a small sample size, no control group, and was not powered for correlation calculations, the conclusions suggested by the fitness and riding performance changes after 8 weeks of cross training are reasonable. The results strongly support the efficacy of a cross training program for equestrian athletes as multiple fitness and sport-specific performance variables improved following the intervention. While both muscular strength and endurance improved, muscular endurance appears to potentially correlate most with improvements in Rider's Effective Use of Aids and overall performance. A strength training intervention, like the one of the current study, was feasible, well liked, and promoted positive muscular fitness adaptations that appear to positively influence riding performance. In conclusion, a home-based isometric exercise training program targeting muscles used during riding is a feasible exercise intervention for amateur equestrians in the sport of dressage. Furthermore, the results of this study suggest that this home-based intervention promotes positive changes in muscular fitness, which appear to have positively influenced riding performance. Due to the relatively small sample size and a lack of a control group, further studies should be conducted to confirm the results of this current study. 


\section{Future Research}

As this study is the first of it's kind, there are many opportunities for future research. Primarily, a larger sample size with a control group would be the next step to confirm the findings of the current study. A longitudinal study of performances of riders who do and don't cross train would help provide a long-term perspective of equestrian training habits and their impact on performance. Additionally, a cross-training intervention with the intention of improving body composition through modified dietary choices and improved physical activity is warranted. This study, in conjunction with prior studies, has demonstrated that equestrians exhibit relatively high, and potentially dangerous, proportions of body fat. Improving body composition of equestrians could not only benefit riding performance but overall health as well.

Although a very complex task, multiple disciplines other than dressage should be studied to better characterize and address the demands of a particular riding style. Riders represent a large age range and encompass multiple skill levels and experience. Thus, riders should also be studied in groups in relation to years of riding experience and biological age. Evaluating highly accomplished riders and beginners would help develop the spectrum of the sport and allow for characterization of intermediate riders in a more logical and progressive manner. 


\section{APPENDIX 3.1: STUDY BROCHURE \\ DRESSAGE RIDERS NEEDED FOR A RESEARCH STUDY}

If you are 40 or older and are interested in learning more about participating in an 8-week long strength training exercise intervention designed to improve riding-specific muscles, please contact:

$$
\begin{gathered}
\text { Jordan T. Lee } \\
\text { jlee25@live.unc.edu } \\
\text { 919-215-1150 }
\end{gathered}
$$

If eligible, you will receive 2 FREE, Judged Training Level Rider Tests and more information about your level of physical fitness!

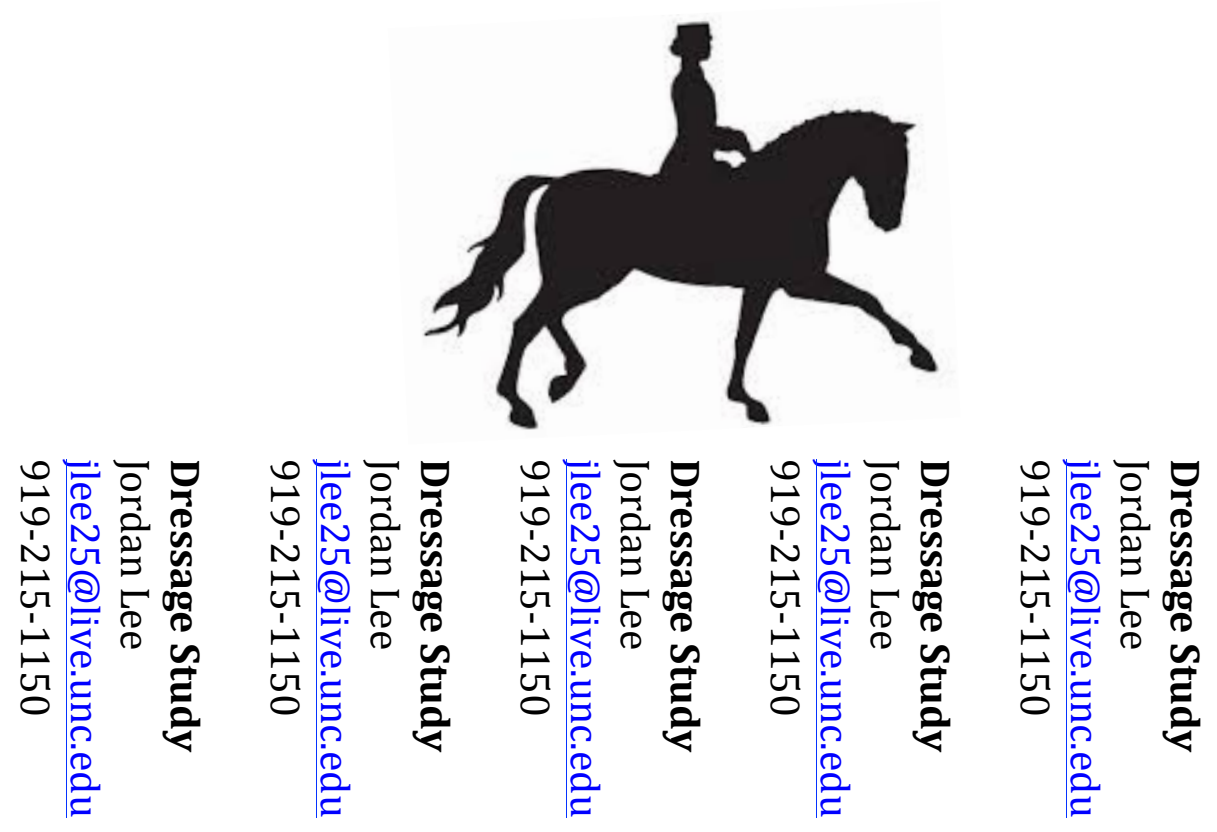




\section{APPENDIX 3.2: PREASSESSMENT GUIDELINES}

\section{Pre-Assessment Guidelines}

Please adhere to the following guidelines prior to your scheduled appointment at the Applied Physiology Lab at the University of North Carolina in Chapel Hill, NC on

1. Please do not exercise for 12 hours prior to your appointment

2. Please do not consume alcohol for 48 hours prior to your appointment

3. Please do not consume caffeine for 24 hours prior to your appointment

4. Please do not eat for 2 hours prior to your appointment

5. Please stay properly hydrated for 48 hours prior to your appointment

6. Please get 6-8 hours of sleep the night before your appointment 


\section{APPENDIX 3.3: PHYSICAL ACTIVITY READINESS QUESTIONNAIRE (PAR-Q) \\ Physical Activity Readiness Questionnaire - PAR-Q \\ (revised 2002)

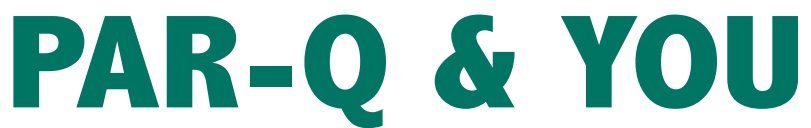

(A Questionnaire for People Aged 15 to 69)

Regular physical activity is fun and healthy, and increasingly more people are starting to become more active every day. Being more active is very safe for most people. However, some people should check with their doctor before they start becoming much more physically active.

If you are planning to become much more physically active than you are now, start by answering the seven questions in the box below. If you are between the ages of 15 and 69 , the PAR-Q will tell you if you should check with your doctor before you start. If you are over 69 years of age, and you are not used to being very active, check with your doctor.

Common sense is your best guide when you answer these questions. Please read the questions carefully and answer each one honestly: check YES or NO.

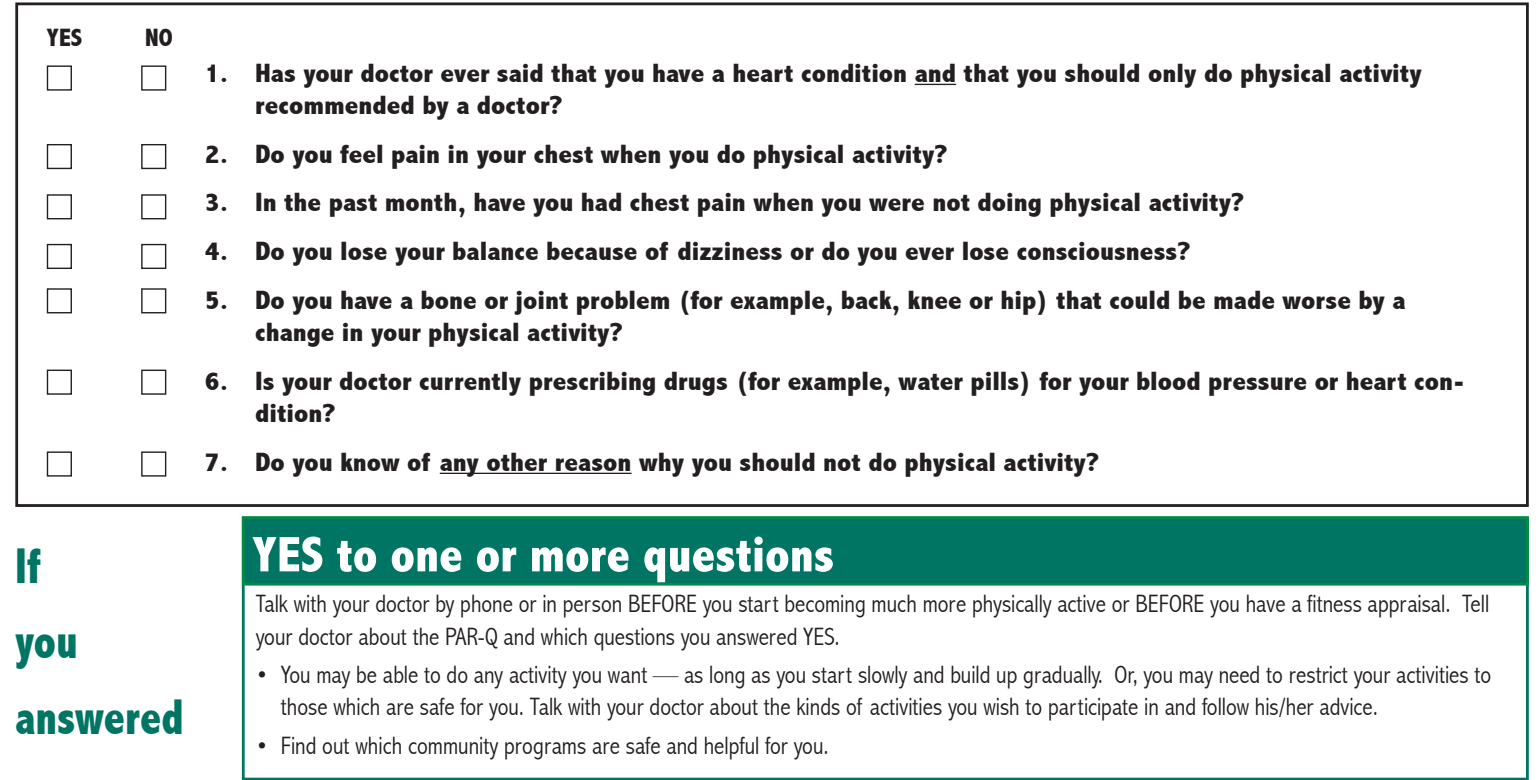

\section{NO to all questions}

If you answered NO honestly to all PAR-Q questions, you can be reasonably sure that you can:

- start becoming much more physically active - begin slowly and build up gradually. This is the safest and easiest way to go.

- take part in a fitness appraisal - this is an excellent way to determine your basic fitness so that you can plan the best way for you to live actively. It is also highly recommended that you have your blood pressure evaluated. If your reading is over 144/94, talk with your doctor before you start becoming much more physically active.

\section{DELAY BECOMING MUCH MORE ACTIVE:}

- if you are not feeling well because of a temporary illness such as a cold or a fever - wait until you feel better; or

- if you are or may be pregnant - talk to your doctor before you start becoming more active.

PLEASE NOTE: If your health changes so that you then answer YES to any of the above questions, tell your fitness or health professional. Ask whether you should change your physical activity plan.

Informed Use of the PAR-Q: The Canadian Society for Exercise Physiology, Health Canada, and their agents assume no liability for persons who undertake physical activity, and if in doubt after completing this questionnaire, consult your doctor prior to physical activity.

No changes permitted. You are encouraged to photocopy the PAR-Q but only if you use the entire form.

NOTE: If the PAR-Q is being given to a person before he or she participates in a physical activity program or a fitness appraisal, this section may be used for legal or administrative purposes.

"I have read, understood and completed this questionnaire. Any questions I had were answered to my full satisfaction."

NAME

SIGNATURE

SIGNATURE OF PARENT

or GUARDIAN (for participants under the age of majority)

DATE

WITNESS

Note: This physical activity clearance is valid for a maximum of 12 months from the date it is completed and becomes invalid if your condition changes so that you would answer YES to any of the seven questions. 


\section{APPENDIX 3.4: MEDICAL HISTORY QUESTIONNAIRE}

\section{Health History Questionnaire}

Please answer the following questions to the best of your ability. For the following questions, unless otherwise indicated, circle the single best choice for each question. As is customary, all of your responses are completely confidential and may only be used in group summaries and/or reports. All information collected is subject to the Privacy Act of 1974. If you have any physical handicaps or limitations that would require special assistance with this questionnaire, please let your trainer know. This form is in accordance with the American College of Sports Medicine guidelines for risk stratification when followed correctly by your trainer. Your trainer should be certified with a national organization in order to use these forms correctly.

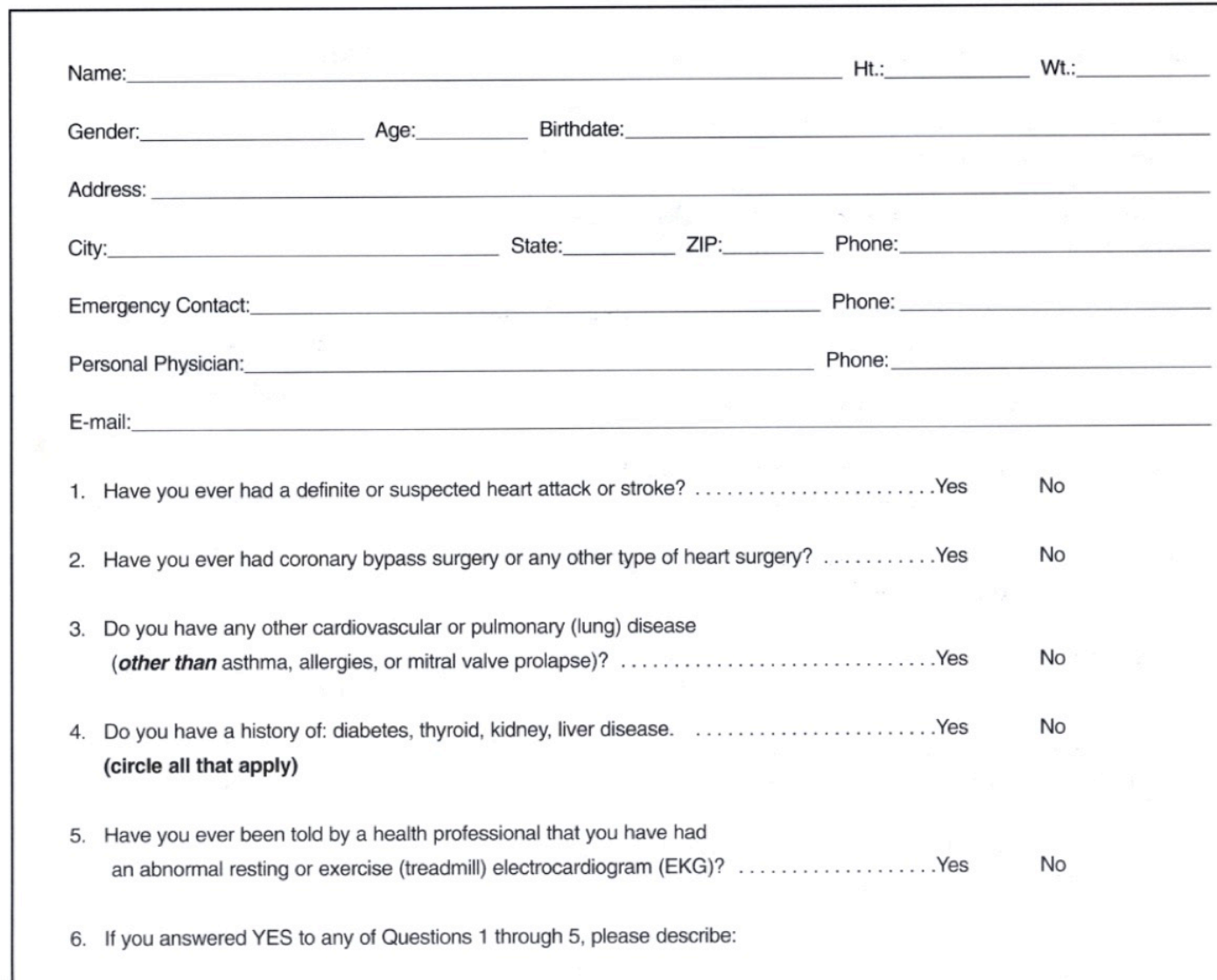

○ Copyrighted by Premier Performance, Inc. 1996

Unauthorized changes or resale is prohibited without permission of PPI

Page 1 of 4 revised $11 / 18 / 03$ $\mathrm{P} 04-020$ 
7. Do you currently have any of the following:

a. pain or discomfort in the chest or surrounding areas that occurs

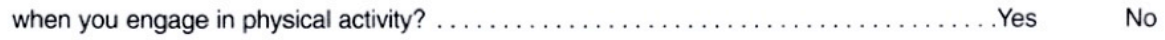

b. shortness of breath $\ldots \ldots \ldots \ldots \ldots \ldots \ldots \ldots \ldots \ldots \ldots \ldots \ldots \ldots \ldots \ldots \ldots \ldots$ Y. No

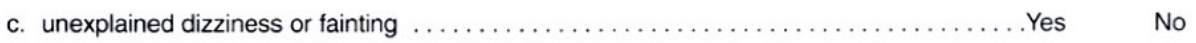

d. difficulty breathing at night except in upright position $\ldots \ldots \ldots \ldots \ldots \ldots \ldots \ldots \ldots$. Y . . . . . . .

e. swelling of the ankles (recurrent and unrelated to injury) $\ldots \ldots \ldots \ldots \ldots \ldots \ldots \ldots$. . . . N . .

f. heart palpitations (irregularity or racing of the heart on more than one occasion) ........ Yes No

g. pain in the legs that causes you to stop walking (claudication) $\ldots \ldots \ldots \ldots \ldots \ldots \ldots$. . . . . . . . . .

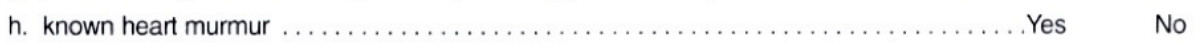

Have you discussed any of the above with your personal physician? .............. Yes No

8. Are you pregnant or is it likely that you could be pregnant at this time? .............. Yes No If yes, what is your expected due date?

9. Have you had surgery or been diagnosed with any disease in the past 3 months? ........ Yes No If yes, please list date and surgery/disease

10. Have you had high blood cholesterol or abnormal lipids within the past 12 months or are you taking medication to control your lipids? . . . . . . . . . . . . . . . . . .

11. Do you currently smoke cigarettes or have quit within the past 6 months? ........... Yes

12. Have your father or brother(s) had heart disease prior to age 55 OR mother or sister(s) had heart disease prior to age 65 ? . . . . . . . . . . . . . . Yes

13. Within the past 12 months, has a health professional told you that you have high blood pressure (systolic $\geq 140$ OR diastolic $\geq 90$ )?

14. Currently, do you have high blood pressure or within the past 12 months, have you taken any medicines to control your blood pressure? . . . . . . . . . . . . . Yes

15. Have you ever been told by a health professional that you have a fasting blood glucose greater than or equal to $110 \mathrm{mg} / \mathrm{dl}$ ?

16. Describe your regular physical activity or exercise program:

type:

$\begin{array}{lll}\text { frequency: } & \text { days per week } & \\ \text { duration: } & \text { minutes } & \\ \text { intensity: Low moderate } & \text { high } \quad \text { (circle one) }\end{array}$

BMI:

17. If you have answered YES to any of questions 7-16, please describe: 
18. Are you currently under any treatment for any blood clots? $\ldots \ldots \ldots \ldots \ldots \ldots \ldots \ldots \ldots \ldots$. Yes No

19. Do you have problems with bones, joints, or muscles that may be aggravated with exercise? ........ Yes No

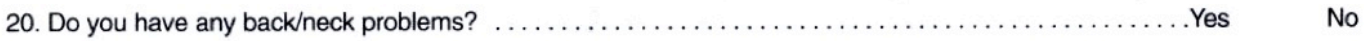

21 Have you been told by a health professional that you should not exercise? $\ldots \ldots \ldots \ldots \ldots \ldots \ldots$. Yes No

22. Are you currently being treated for any other medical condition by a physician? . . . . . . . . . . . . Yes

23. Are there any other conditions (mitral valve prolapse, epilepsy, history of rheumatic fever, asthma, cancer, anemia, hepatitis, etc.) that may hinder your ability to exercise? ............... Yes No

24. During the past six months, have you experienced any unexplained weight loss or gain

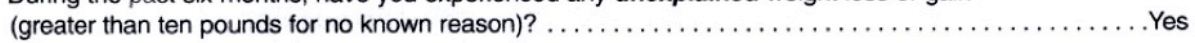

25. If you have answered YES to any of questions 18-24, please describe:

26. Please list below all prescription and over-the-counter medications you are currently taking:

Medicine:
Reason for taking:

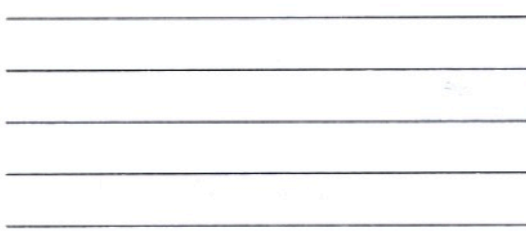

Dosage:

Amount/Frequency:

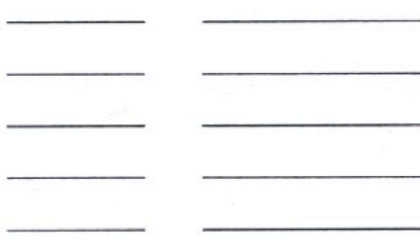

27. Are there any medicines that your physician has prescribed to you in the past

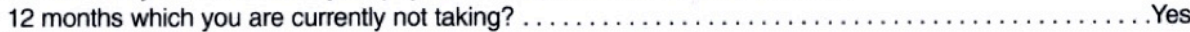

I have answered the Health History Questionnaire questions accurately and completely. I understand that my medical history is a very important factor in the development of my fitness/wellness program. I understand that certain medical or physical conditions which are known to me, but that I do not disclose to my trainer, may result in serious injury to me. If any of the above conditions change, I will immediately inform my trainer of those changes. I, knowingly and willingly, assume all risks of injury resulting from my failure to disclose accurate, complete, and updated information in accordance with the attached questionnaire. I also understand that in order to properly risk stratify my Health History Questionnaire, my trainer should have a minimum of a national certification as a personal trainer. My trainer also verbally explained this statement to me to my understanding.

Client's Signature: Date:

Trainer's Signature: Date: 


\title{
APPENDIX 3.5: INTERNATIONAL PHYSICAL ACTIVITY QUESTIONNAIRE (IPAQ) \\ INTERNATIONAL PHYSICAL ACTIVITY QUESTIONNAIRE
}

(August 2002)

\section{SHORT LAST 7 DAYS SELF-ADMINISTERED FORMAT}

\author{
FOR USE WITH YOUNG AND MIDDLE-AGED ADULTS (15-69 years)
}

The International Physical Activity Questionnaires (IPAQ) comprises a set of 4 questionnaires. Long ( 5 activity domains asked independently) and short (4 generic items) versions for use by either telephone or self-administered methods are available. The purpose of the questionnaires is to provide common instruments that can be used to obtain internationally comparable data on health-related physical activity.

\section{Background on IPAQ}

The development of an international measure for physical activity commenced in Geneva in 1998 and was followed by extensive reliability and validity testing undertaken across 12 countries (14 sites) during 2000. The final results suggest that these measures have acceptable measurement properties for use in many settings and in different languages, and are suitable for national population-based prevalence studies of participation in physical activity.

\section{Using IPAQ}

Use of the IPAQ instruments for monitoring and research purposes is encouraged. It is recommended that no changes be made to the order or wording of the questions as this will affect the psychometric properties of the instruments.

\section{Translation from English and Cultural Adaptation}

Translation from English is supported to facilitate worldwide use of IPAQ. Information on the availability of IPAQ in different languages can be obtained at www.ipaq.ki.se. If a new translation is undertaken we highly recommend using the prescribed back translation methods available on the IPAQ website. If possible please consider making your translated version of IPAQ available to others by contributing it to the IPAQ website. Further details on translation and cultural adaptation can be downloaded from the website.

\section{Further Developments of IPAQ}

International collaboration on IPAQ is on-going and an International Physical Activity Prevalence Study is in progress. For further information see the IPAQ website.

\section{More Information}

More detailed information on the IPAQ process and the research methods used in the development of IPAQ instruments is available at www.ipaq.ki.se and Booth, M.L. (2000). Assessment of Physical Activity: An International Perspective. Research Quarterly for Exercise and Sport, 71 (2): s114-20. Other scientific publications and presentations on the use of IPAQ are summarized on the website. 
We are interested in finding out about the kinds of physical activities that people do as part of their everyday lives. The questions will ask you about the time you spent being physically active in the last 7 days. Please answer each question even if you do not consider yourself to be an active person. Please think about the activities you do at work, as part of your house and yard work, to get from place to place, and in your spare time for recreation, exercise or sport.

Think about all the vigorous activities that you did in the last 7 days. Vigorous physical activities refer to activities that take hard physical effort and make you breathe much harder than normal. Think only about those physical activities that you did for at least 10 minutes at a time.

1. During the last $\mathbf{7}$ days, on how many days did you do vigorous physical activities like heavy lifting, digging, aerobics, or fast bicycling?

days per week

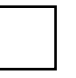

No vigorous physical activities $\longrightarrow$ Skip to question 3

2. How much time did you usually spend doing vigorous physical activities on one of those days?

hours per day minutes per day

$\square$ Don't know/Not sure

Think about all the moderate activities that you did in the last 7 days. Moderate activities refer to activities that take moderate physical effort and make you breathe somewhat harder than normal. Think only about those physical activities that you did for at least 10 minutes at a time. 
3. During the last $\mathbf{7}$ days, on how many days did you do moderate physical activities like carrying light loads, bicycling at a regular pace, or doubles tennis? Do not include walking.

\section{days per week}

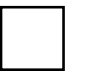

No moderate physical activities $\longrightarrow$ Skip to question 5

4. How much time did you usually spend doing moderate physical activities on one of those days?

hours per day minutes per day

$\square$ Don't know/Not sure

Think about the time you spent walking in the last 7 days. This includes at work and at home, walking to travel from place to place, and any other walking that you might do solely for recreation, sport, exercise, or leisure.

5. During the last $\mathbf{7}$ days, on how many days did you walk for at least 10 minutes at a time?

days per week

No walking $\longrightarrow$ Skip to question 7

6. How much time did you usually spend walking on one of those days? hours per day 
minutes per day

$\square$ Don't know/Not sure

The last question is about the time you spent sitting on weekdays during the last 7 days. Include time spent at work, at home, while doing course work and during leisure time. This may include time spent sitting at a desk, visiting friends, reading, or sitting or lying down to watch television.

7. During the last $\mathbf{7}$ days, how much time did you spend sitting on a weekday?
hours per day minutes per day
$\square$ Don't know/Not sure

This is the end of the questionnaire, thank you for participating. 


\section{APPENDIX 3.6: USEF TRAINING LEVEL RIDER TEST}

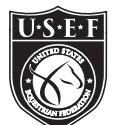

\section{USEF TRAINING LEVEL RIDER TEST}

UNITED STATES EQUESTRIAN FEDERATION

Purpose: To confirm that the rider sits in the correct posture and alignment and shows correct mechanics in walk, rising trot and canter. The seat is sufficiently independent for the rider to maintain a steady, elastic rein contact and encourage the horse to stretch into that contact. The horse is ridden actively forward showing impulsion and balance required for the level, bends equally to the left and right sides on turns and circles, and makes smooth, willing transitions.

All trot work to be ridden rising except for a few steps (4-8) of sitting trot during transitions. Transitions to halt may be performed through the walk.

READER PLEASE NOTE: Anything in parentheses should not be read.
Arena: Small/Standard

Actual Average Time: 3:30/5:00

Recommended Scheduled Time: 6:00/8:00

Maximum Possible Points: 100

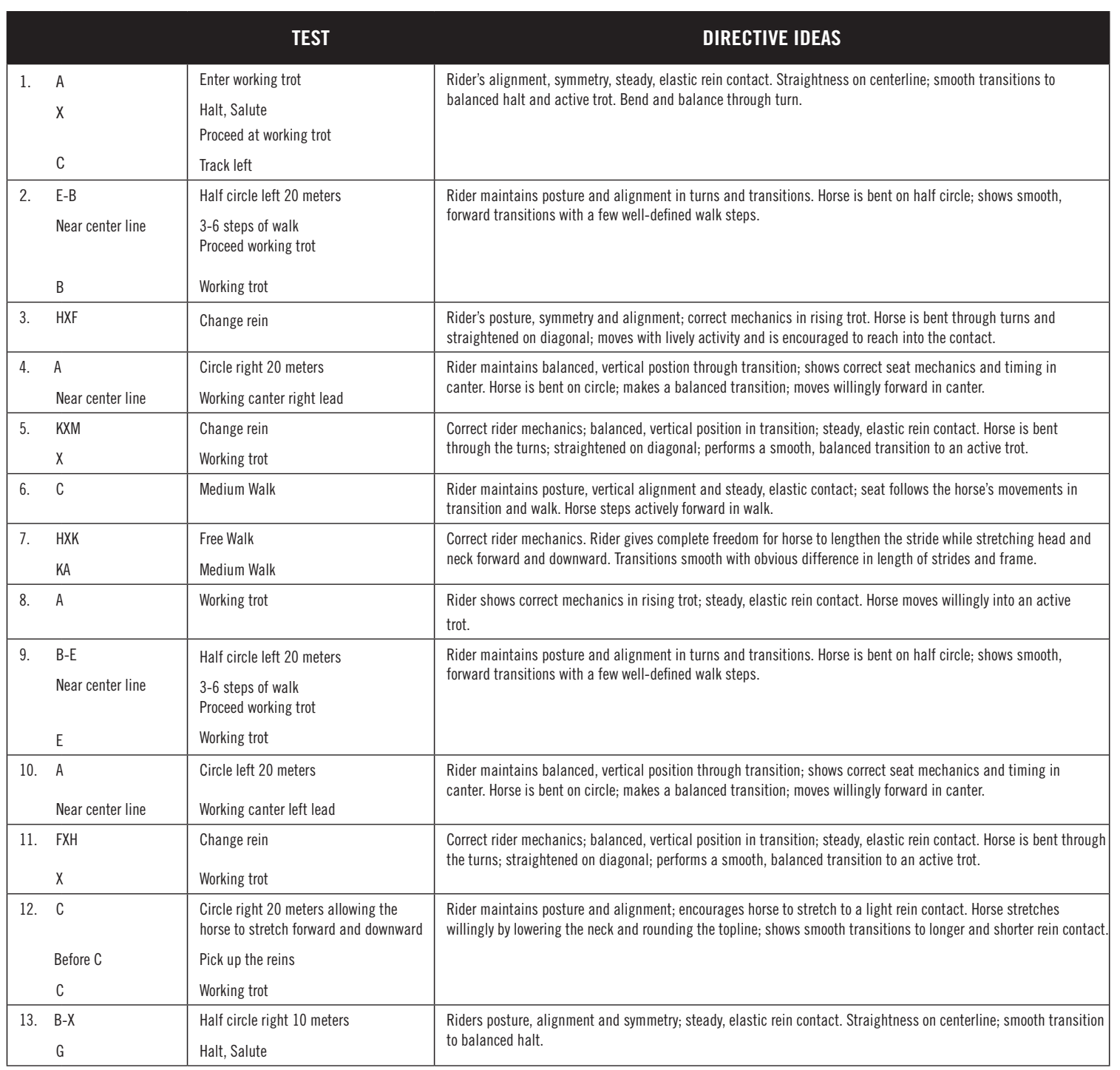

Leave arena at $A$ in walk on a long rein 


\begin{tabular}{|c|c|c|c|}
\hline COLLECTIVE MARKS & $\begin{array}{l}\text { SCORE } \\
\end{array}$ & COEF & TOTAL \\
\hline $\begin{array}{l}\text { Rider's Position } \\
\text { The ridede's ear, shoulder, hip and heel are aligned vertically when sitting at all gaits. The } \\
\text { trunk is slightly in front of the vertical in rising trot. When seen from in front or behind } \\
\text { the rider is straight and symmetrical with even shoulders, hips and stirrups. The rider } \\
\text { sits in harmony with the mechanics of each gait. The hands maintain a steady, elastic } \\
\text { contact with the horse's mouth. }\end{array}$ & & 2 & \\
\hline $\begin{array}{l}\text { Rider's Correct and Effective Use of the Aids } \\
\text { The rider prepares for and performs the movements using subtle, tactful and effective } \\
\text { aids. The horse is appropriately bent through the turns and on circles and is straight } \\
\text { when moving on straight lines. The horre responds willingly giving the impression of } \\
\text { clear communication between rider and horse. }\end{array}$ & & 2 & \\
\hline $\begin{array}{l}\text { Horse's Response and Performance } \\
\text { The horse's training appears to be following the principles established by the Pyramid } \\
\text { of Training. The horse moves actively forward with a consistent tempo in each gait and } \\
\text { reaches confidently to the bit. The transitions are performed willingly and smoothly. The } \\
\text { rider demonstrates horse's clear reactivity to both lateral and longitudinal aid influence. }\end{array}$ & & 2 & \\
\hline $\begin{array}{l}\text { Accuracy of the Exercises } \\
\text { The geometry of the movements is correct in terms of their size, shape and placement } \\
\text { in the arena. The circles and half circles are round, have the correct diameter and they } \\
\text { originate and termininate at the correct place. The corners are performed as one quarter } \\
\text { of a } 10 \text { meter circle. }\end{array}$ & & 2 & \\
\hline $\begin{array}{l}\text { Harmony between Rider and Horse } \\
\text { Both horse and rider appear calm, focused and confident. They perform competently at } \\
\text { the level and are pleasant to watch. }\end{array}$ & & 2 & \\
\hline $\begin{array}{l}\text { Errors: } \\
\text { For Rider tests, the deduction for an error shall be: } \\
\text { (1) First enror: Score reduced by } 0.5 \text { points } \\
\text { (2) Second error: Score reduced by an additional } 1.0 \text { points } \\
\text { (3) Third error: Elimination } \\
\text { Marks from } 0 \text { to } 10 \text {, decimals allowed (e.g. } 7.3 \text { or } 8.7 \text { ) } \\
\text { Percentage is the same as total points but is shown with } 3 \text { decimal places } \\
\text { (e.g. } 65.1 \text { points becomes } 65.100 \% \text { ) }\end{array}$ & $\begin{array}{l}\text { Subtotal: } \quad(-\square) \\
\text { Errors: } \\
\text { Total Points: } \quad- \\
\text { Percentage } \quad\end{array}$ & & \\
\hline Comments: & & & \\
\hline
\end{tabular}

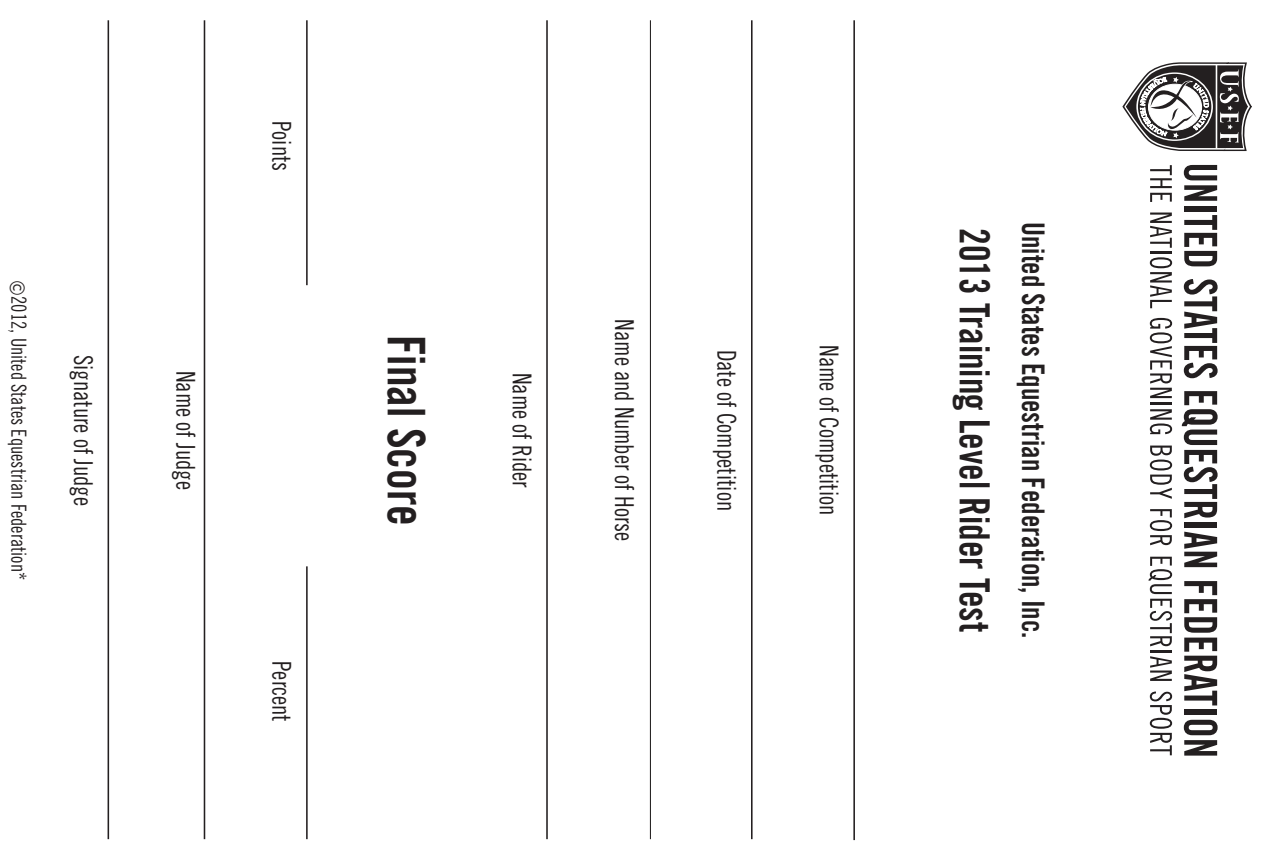




\title{
APPENDIX 3.7: PREASSESSMENT QUESTIONNAIRE
}

\author{
Subject ID: \\ Date: \\ Circle One: Pre-Test Post-Test
}

\section{Pre-Assessment Questionnaire}

Please circle the appropriate response for each question below. Y=yes, N=no

1. Have you exercised in the past 12 hours?

Y N

2. Have you consumed alcohol in the past 48 hours?

Y N

3. Have you consumed caffeine in the past 24 hours?

Y N

4. Have you eaten in the past 2 hours?

Y N

5. Have you stayed hydrated in the past 48 hours?

Y N

6. Did you have 6-8 hours of sleep last night?

Y N




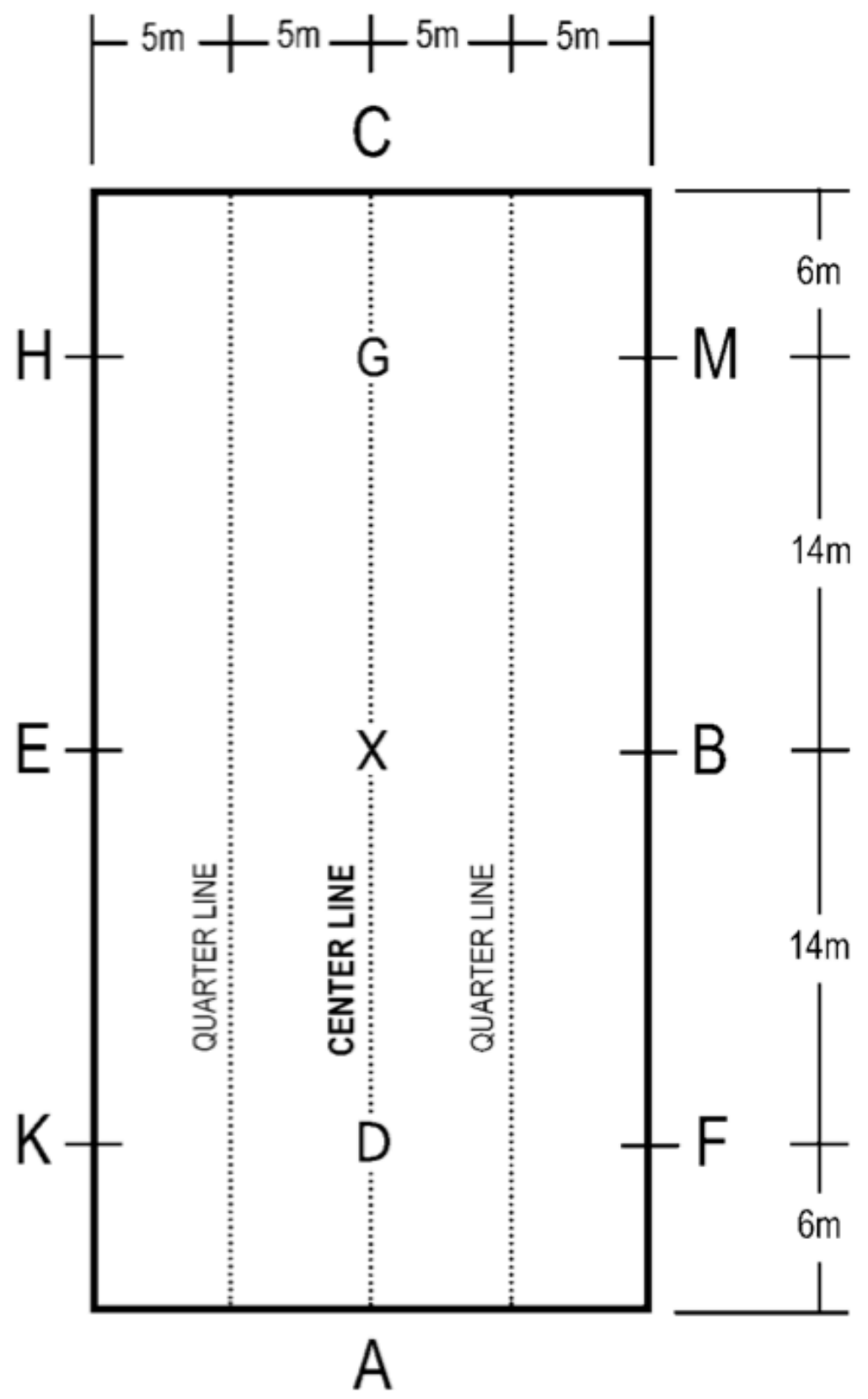

United States Dressage Federation (2013) 4051 Iron Works Parkway, Lexington, KY, 40511 www.usdf.org 


\section{APPENDIX 3.9: FOLLY FARM LIABILITY WAIVER}

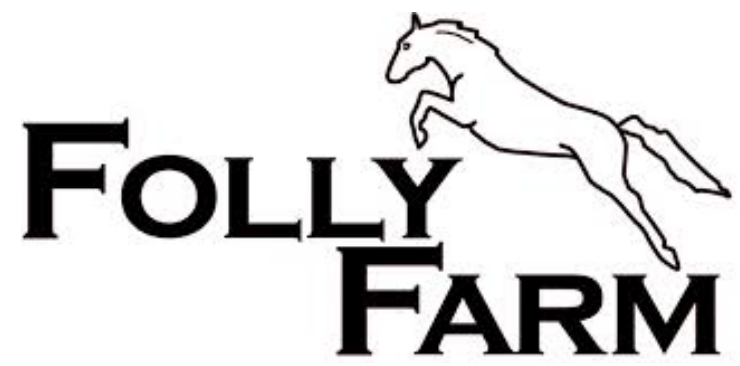

\section{LIABILITY WAIVER}

$\mathrm{I}$, , hereby acknowledge the inherent risks involved in riding horses and in working and being around horses, including the risk of serious bodily injury and possible death, among other risks. I understand that both horse and rider can be injured in the course of normal enjoyment of equestrian activities, including during riding, schooling, competition, regular barn managementnt, grooming and all aspects of regular horse care. I understand that North Carolina law warns and states that, "an equine activity sponsor or equine professional is not liable for an injury to or the death of a participant in equine activities resulting exclusively from the inherent risks of equine activities" (Chapter 99E of the North Carolina Statutes).

I state my intention to ride horses and hereby agree to indemnify and hold harmless Folly Farm or the owners and staff and release them from any liability or responsibility for accidents, damage, inbjury or illness to myself or my horse(s), family members, guests and or any spectators accompanying me.

Signed

Address

Parent or Guardian

Signature 


\title{
APPENDIX 3.10: PARTICIPANT EXERCISE INSTRUCTION MANUAL
}

\section{Exercise Instruction Manual}

\author{
Created By: Jordan T. Lee \\ University of North Carolina Chapel Hill \\ Department of Exercise and Sport Science \\ 2014
}
*Illustrations, descriptions and product information adapted from the 2012 TheraBand Instruction Manual
(The Hygenic Corporation, Akron, $\mathrm{OH}$ )



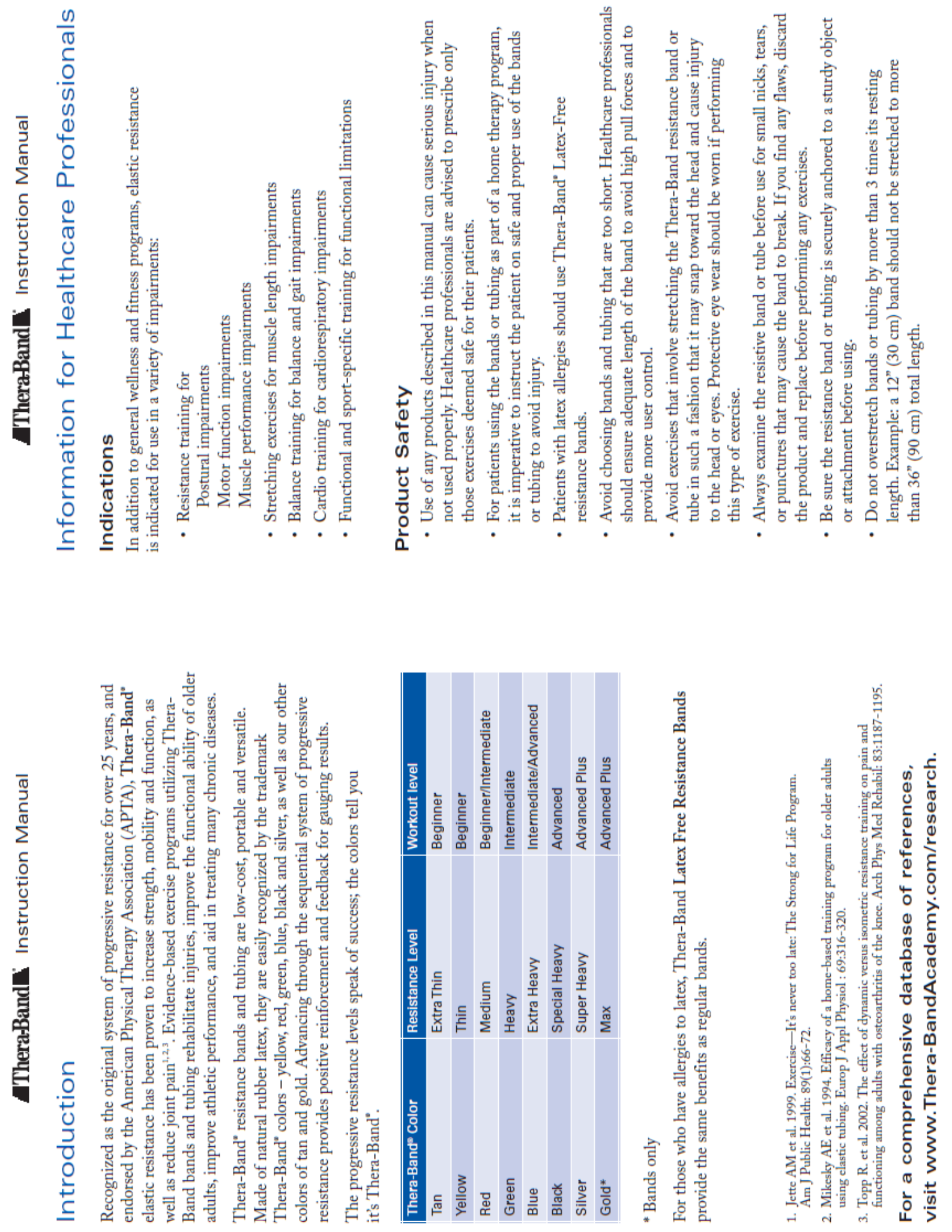

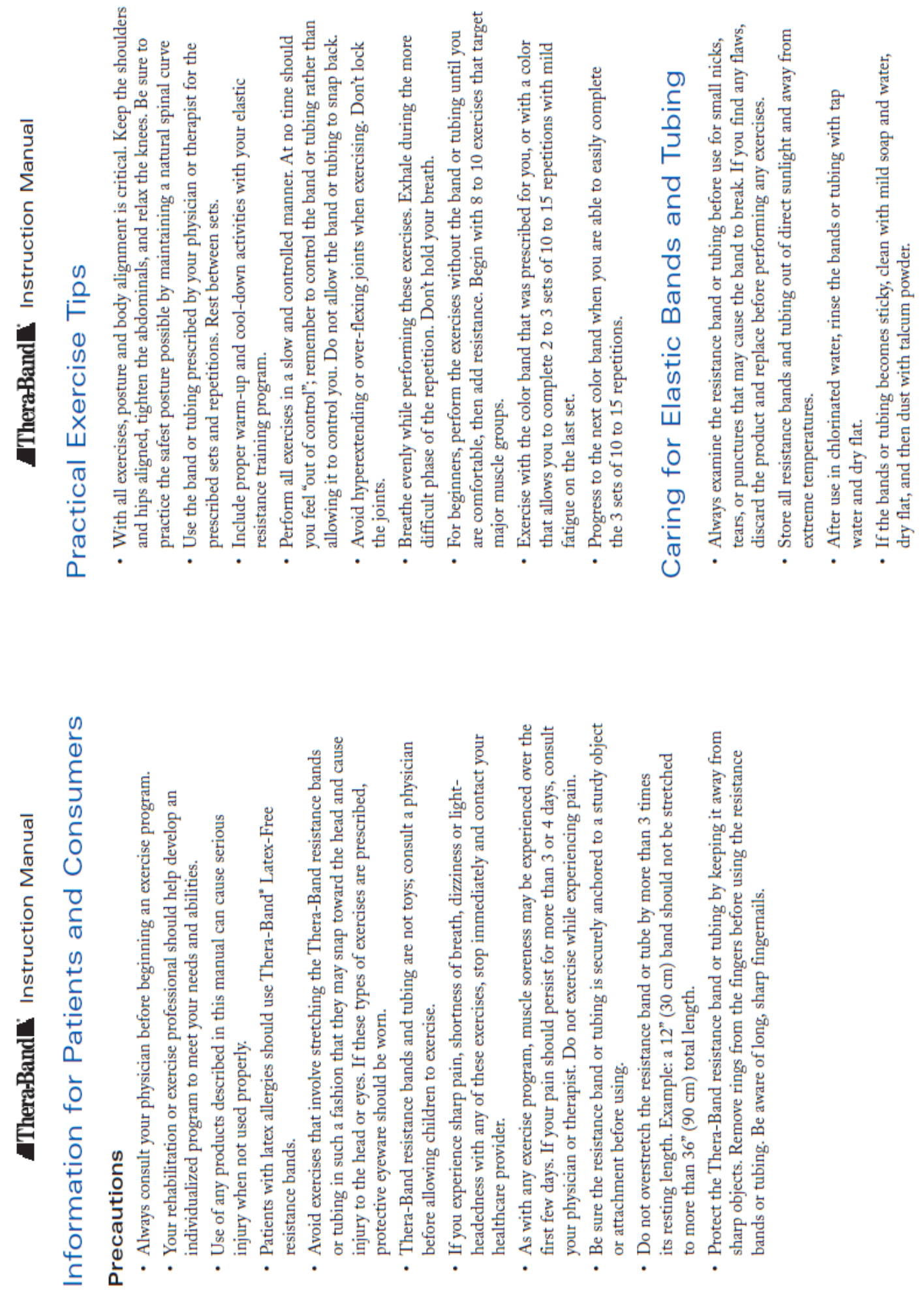

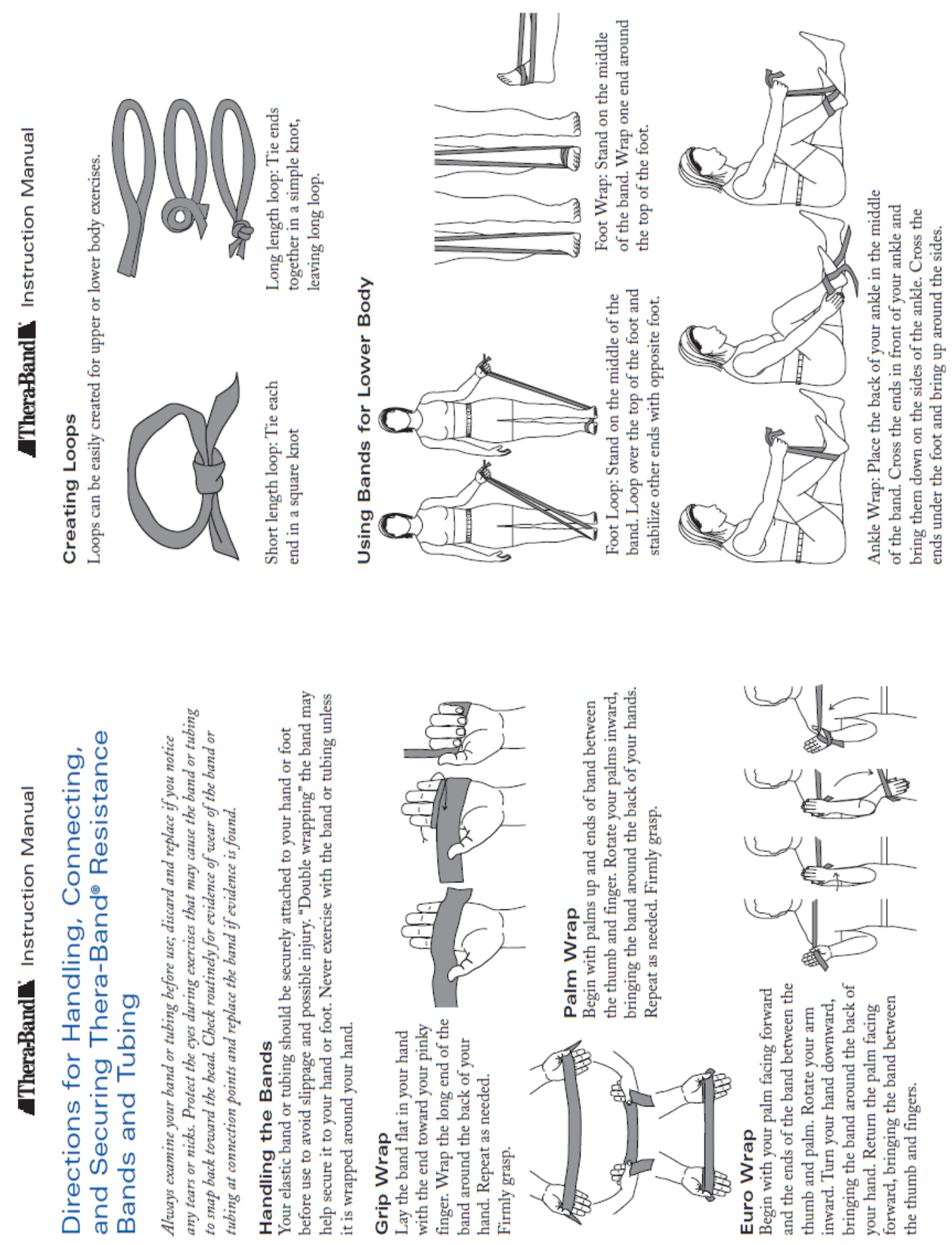


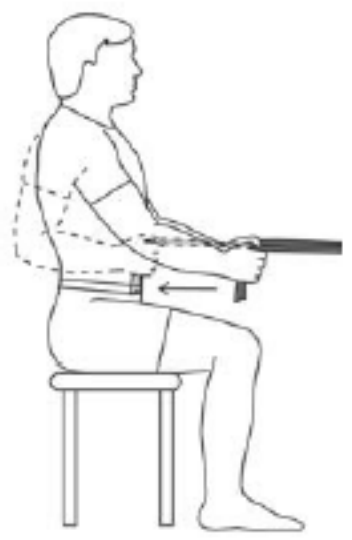

Isometric Seated Row

- Attach elastic to secure object

- Grasp elastic in hands

- Sit in chair with back unsupported, maintaining proper posture

- Keep elbows near sides, elbows bent

- Squeeze shoulder blades together, pulling arms back and hold position

Trunk Curl-Up

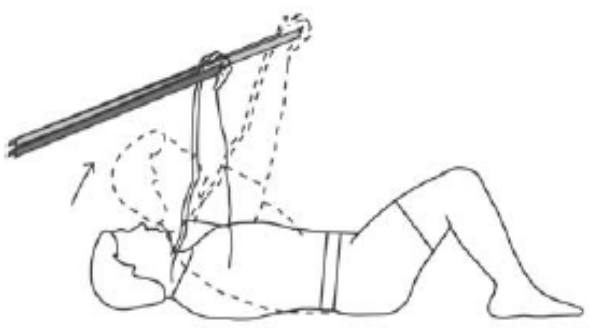

- Securely attach the ends of band to a stationary object near floor

- Lie on back with knees bent, holding ends of bands in hands, arms in front and elbows straight

- Keep hands close together and curl trunk upward, lifting shoulder blades from floor

- Slowly return to starting position and repeat

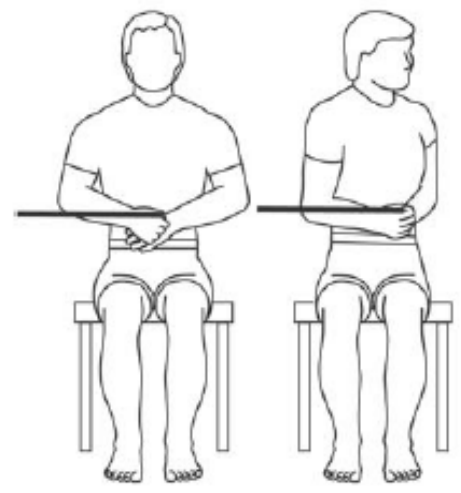

Trunk Twist

- Attach elastic to secure object at waist level

- Sit in chair

- Grasp elastic in both hands, hold elastic at navel

- Twist away from elastic, slowly return to starting position and repeat 

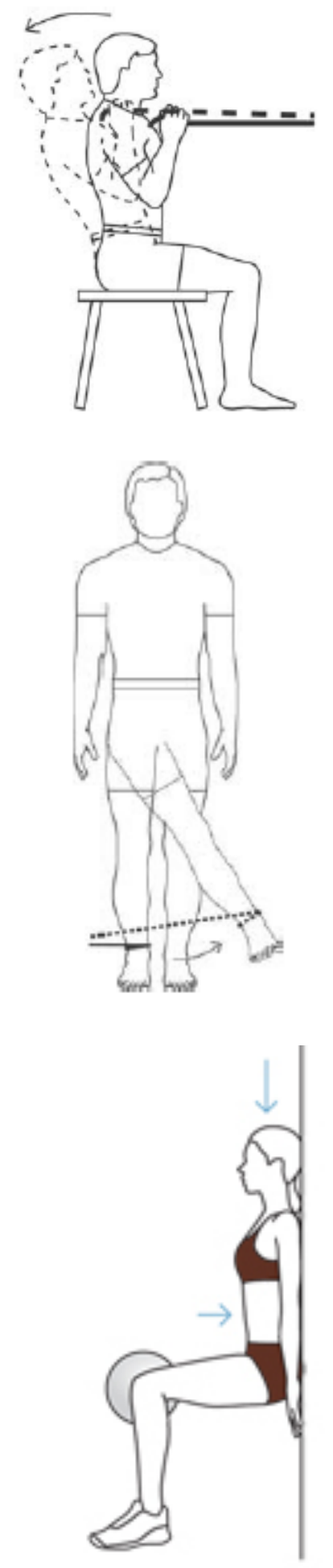

\section{Back Extension}

- Attach elastic to secure object at shoulder level while sitting on stool as shown

- Grasp elastic in hands and hold to chest

- Pull backward, straightening trunk. Return to starting position and repeat

Hip Adduction

- Attach elastic to secure object at ankle level

- Stand with involved leg toward pull, as shown

- Keep knee straight, pull in, moving leg inward, hold the position

Wall Squat with Tennis Ball

- $\quad$ Sit with back against the wall and squat down with knees bent at a 90degree angle

- Squeeze and hold a tennis ball between the knees

- Keep hands and elbows off the thighs, hold the position 
APPENDIX 3.11: PARTICIPANT EXERCISE LOG

\begin{tabular}{|c|c|c|c|c|c|c|c|c|c|}
\hline & 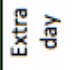 & & $\times$ & $x$ & $\times$ & $x$ & $\times$ & $x$ & \\
\hline & 答 & & $\times$ & $\times$ & $\times$ & $\times$ & $\times$ & $\times$ & \\
\hline & 簽 & & $\times$ & $\times$ & $\times$ & $x$ & $\times$ & $\times$ & \\
\hline & 곰 & & $\times$ & $\times$ & $\times$ & $\times$ & $\times$ & $\times$ & \\
\hline $\begin{array}{l}\text { 咅 } \\
3\end{array}$ & 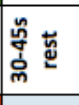 & & 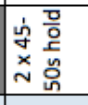 & $\underset{\sim}{\vec{x}}$ & 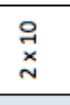 & $\underset{\sim}{\stackrel{\vec{x}}{\sim}}$ & 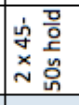 & 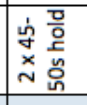 & \\
\hline & 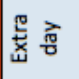 & & $\times$ & $\times$ & $\times$ & $\times$ & $\times$ & $x$ & \\
\hline & $\stackrel{m}{\stackrel{m}{a}}$ & & $\times$ & $\times$ & $\times$ & $\times$ & $\times$ & $\times$ & \\
\hline & 合 & & $\times$ & $\times$ & $x$ & $\times$ & $x$ & $x$ & \\
\hline & 斊 & & $\times$ & $\times$ & $\times$ & $\times$ & $\times$ & $\times$ & \\
\hline 立 & 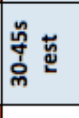 & & 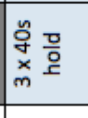 & \begin{tabular}{l}
\multirow{2}{*}{} \\
$\dot{0}$ \\
$\dot{x}$ \\
\end{tabular} & 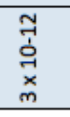 & 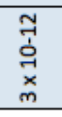 & 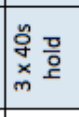 & 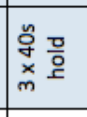 & \\
\hline & 妥亭 & & $\times$ & $\times$ & $\times$ & $\times$ & $\times$ & $\times$ & \\
\hline & 兎 & & $\times$ & $\times$ & $\times$ & $\times$ & $\times$ & $\times$ & \\
\hline & 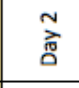 & & $\times$ & $\times$ & $\times$ & $\times$ & $\times$ & $\times$ & \\
\hline & 斊 & & $\times$ & $\times$ & $\times$ & $\times$ & $\times$ & $\times$ & \\
\hline 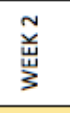 & \begin{tabular}{|l|c|} 
\\
\end{tabular} & & 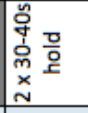 & $\underset{\sim}{\stackrel{n}{x}}$ & $\underset{\sim}{\stackrel{n}{x}}$ & $\underset{\sim}{\stackrel{n}{x}}$ & 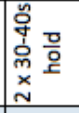 & 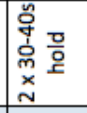 & \\
\hline & $\frac{⿱ 0}{x}$ 흠 & & $\times$ & $\times$ & $\times$ & $\times$ & $\times$ & $\times$ & \\
\hline & $\stackrel{m}{\stackrel{m}{a}}$ & & $\times$ & $\times$ & $\times$ & $\times$ & $\times$ & $\times$ & \\
\hline & 簽 & & $\times$ & $\times$ & $\times$ & $\times$ & $\times$ & $\times$ & \\
\hline & 斊 & & $\times$ & $\times$ & $\times$ & $\times$ & $\times$ & $\times$ & \\
\hline $\begin{array}{l}\overrightarrow{5} \\
\end{array}$ & 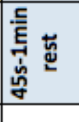 & & 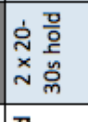 & $\underset{\sim}{\pi}$ & $\underset{\sim}{\mathbb{x}}$ & $\underset{\sim}{\underset{\sim}{x}}$ & 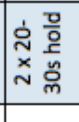 & 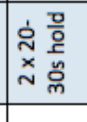 & \\
\hline & 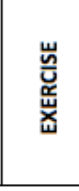 & 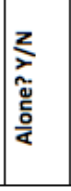 & 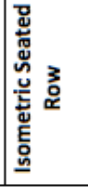 & 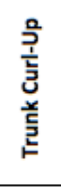 & 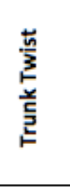 & 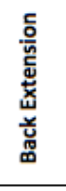 & 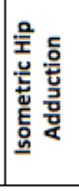 & 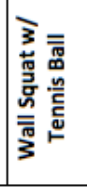 & 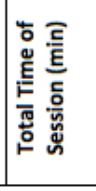 \\
\hline
\end{tabular}

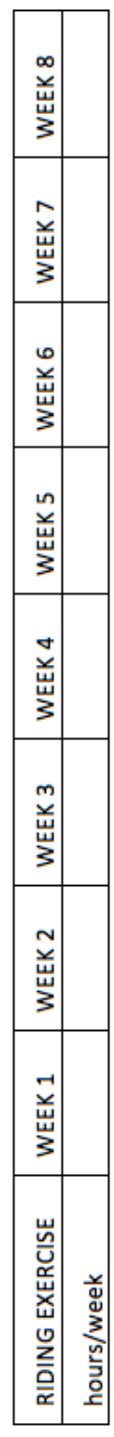




\begin{tabular}{|c|c|c|c|c|c|c|c|c|c|c|c|}
\hline & 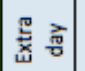 & & $\times$ & $\times$ & $\times$ & $\times$ & $\times$ & $\times$ & & & \\
\hline & त्ञ $m$ & & $\times$ & $\times$ & $\times$ & $\times$ & $\times$ & $\times$ & & & \\
\hline & 흠 $\sim$ & & $\times$ & $\times$ & $\times$ & $\times$ & $\times$ & $\times$ & & & \\
\hline & 高 & & $\times$ & $\times$ & $\times$ & $\times$ & $\times$ & $\times$ & & & \\
\hline \begin{tabular}{|l|} 
\\
嵒 \\
3
\end{tabular} & 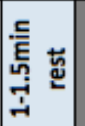 & & 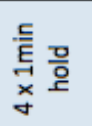 & 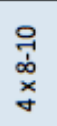 & $\begin{array}{l}\stackrel{9}{a} \\
\infty \\
x \\
x \\
\forall\end{array}$ & $\begin{array}{l}\stackrel{9}{1} \\
\infty \\
\times \\
x \\
x\end{array}$ & \begin{tabular}{l} 
들 \\
$\underset{x}{\mathrm{E}}$ 믕 \\
\multirow{y}{}{}
\end{tabular} & $\begin{array}{l}\text { 들 믕 } \\
\text { 종 }\end{array}$ & & & \\
\hline & $\mid \begin{array}{ll}\frac{2}{x} & > \\
\frac{x}{4} & \frac{\pi}{0}\end{array}$ & & $\times$ & $\times$ & $\times$ & $\times$ & $\times$ & $\times$ & & & \\
\hline & 高 $m$ & & $\times$ & $\times$ & $\times$ & $\times$ & $\times$ & $\times$ & & & \\
\hline & 產 & & $\times$ & $\times$ & $\times$ & $\times$ & $\times$ & $\times$ & & \begin{tabular}{l|}
$\infty$ \\
㟧|
\end{tabular} & \\
\hline & बे & & $\times$ & $\times$ & $\times$ & $\times$ & $\times$ & $\times$ & & 3 & \\
\hline 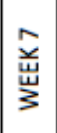 & 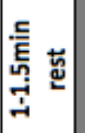 & & 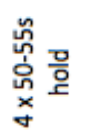 & $\begin{array}{l}\stackrel{9}{1} \\
\infty \\
\times \\
\times \\
\forall\end{array}$ & 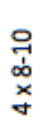 & $\begin{array}{l}\stackrel{9}{1} \\
\infty \\
\times \\
x \\
x\end{array}$ & 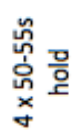 & 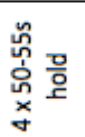 & & $\begin{array}{l}\hat{y} \\
\text { 慈 }\end{array}$ & \\
\hline & 焉 & & $\times$ & $\times$ & $\times$ & $\times$ & $\times$ & $\times$ & & $\begin{array}{l}6 \\
\text { 朔 }\end{array}$ & \\
\hline & त्ञ $m$ & & $\times$ & $\times$ & $\times$ & $\times$ & $\times$ & $\times$ & & & \\
\hline & 命 & & $\times$ & $\times$ & $\times$ & $\times$ & $\times$ & $\times$ & & 恙 & \\
\hline & 商 & & $\times$ & $\times$ & $\times$ & $\times$ & $\times$ & $\times$ & & & \\
\hline 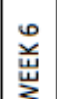 & 毫 & & 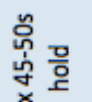 & 芒 & 草 & ‡ั1 & 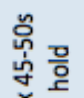 & 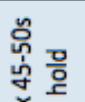 & & 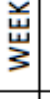 & \\
\hline & & & $\hat{\sigma}$ & & & 于 & $\hat{\sigma}$ & $\hat{\sigma}$ & & & \\
\hline & 焉 & & $\times$ & $\times$ & $\times$ & $\times$ & $\times$ & $\times$ & & 总| & \\
\hline & 商 $m$ & & $\times$ & $\times$ & $\times$ & $\times$ & $\times$ & $\times$ & & $\sim$ & \\
\hline & 商 $\sim$ & & $\times$ & $\times$ & $\times$ & $\times$ & $\times$ & $\times$ & & 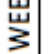 & \\
\hline & 裔 & & $\times$ & $\times$ & $\times$ & $\times$ & $\times$ & $\times$ & & $\overrightarrow{\mathrm{u}}$ & \\
\hline$\approx$ & & & & ๓ & ๓ & น & & & & 3 & \\
\hline 岀 & $\underset{-E}{E}$ & & $\underset{m}{\times}$ & $\underset{m}{\vec{x}}$ & $\underset{m}{\vec{x}}$ & $\underset{m}{\vec{x}}$ & $\times$ 옹 & $\underset{m}{\times}$ 오 & & 㞦 & \\
\hline & 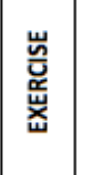 & $\begin{array}{l}z \\
z \\
\bar{d} \\
\frac{\partial}{\alpha} \\
\frac{0}{\alpha}\end{array}$ & 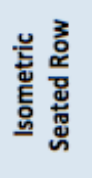 & 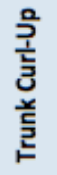 & 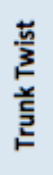 & 总 & 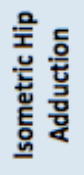 & 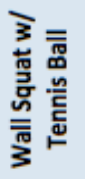 & 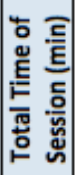 & 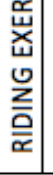 & 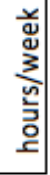 \\
\hline
\end{tabular}




\section{APPENDIX 3.12: STRETCHING GUIDE}

\section{Whole-Body Stretching}

To be performed following a $\sim 6$ min warm-up (walking, biking, etc.) and before the strength training exercises.

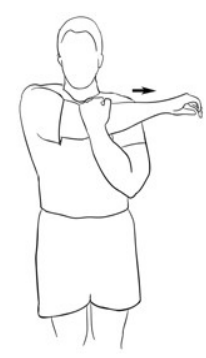

Arm Cross: Pull one extended arm across your chest with the other arm. Hold for 10-20 seconds, release and switch arms.

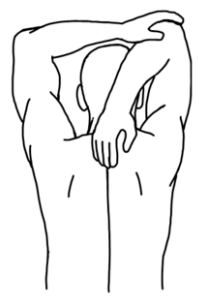

Bent Elbow: Bend the right arm with elbow pointed up and hand behind the neck (like you are scratching your back), grasp the bent elbow with the left hand and gently pull to the left side of your body. Hold for 10-20 seconds, release and switch arms.

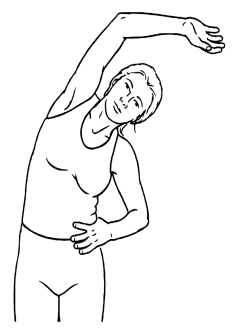

Side Stretch: Place left hand on hip, stretch right arm overhead and lean slowly to the left side, gently stretching the right side of your core. Hold for 10-20 seconds, release and switch arms/sides.

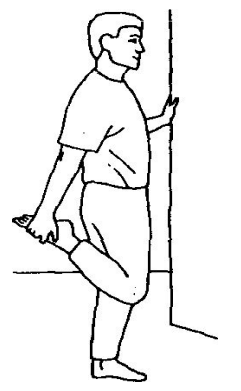

Quadriceps stretch: Hold a sturdy object for balance, bend your right knee putting your heel to your buttocks and grasp your foot. Gently stretch your bent knee towards the floor, feeling the stretch in the front of your thigh. Hold for 10-20 seconds, release and switch legs.

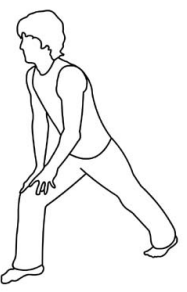

Calf stretch: Stand with one leg in front of the other, bend the front knee into a partial lunge and straightening the back leg, gently stretching the back of your lower leg (calf). Hold for 10-20 seconds, release and switch legs. 


\section{APPENDIX 3.13: INTERVENTION ENJOYMENT QUESTIONNAIRE}

\section{Subject ID:}

1. Did you enjoy this strength training intervention with resistance bands?

Yes No

2. How likely are you to continue using the resistance bands to improve your strength?
Very Likely
Maybe
Not Likely

3. What did you like most about this strength training intervention?

Please describe:

4. What did you like least about this strength training intervention and how could we improve it?

Please describe:

5. Do you think this strength training intervention positively impacted your riding? 


\section{REFERENCES}

About Dressage. (2014). Retrieved March 23, 2014 from http://www.fei.org/fei/disc/dressage/about-dressage

Alfredson, H., Hedberg, G., Bergstrom, E., Nordstrom, P. and Lorentzon, R. (1998). High thigh muscle strength but not bone mass in young horseback-riding females. Calcified Tissue International, 62. 497-501.

Andersen, L.L., Andersen, C.H., Mortensen, O.S., Poulsen, O.M., Bjornlund, I.B.T. and Zebis, M.K. (2010). Muscle activation and perceived loading during rehabilitation exercises: comparison of dumbbells and elastic resistance. Physical Therapy, 90(4), 538-549.

Byström, A., Rhodin, M., von Peinen, K., Weishaupt, M.A., Roepstorff, L. (2009). Basic kinematics of the saddle and rider in high-level dressage horses trotting on a treadmill. Equine Veterinary Journal, 41(3). 280-284.

Colado, J. C., Garcia-Masso, X., Rogers, M. E., Tella, V., Benavent, J., \& Dantas, E. H. (2012). Effects of Aquatic and Dry Land Resistance Training Devices on Body Composition and Physical Capacity in Postmenopausal Women. Journal of Human Kinetics, 32, 185-195. doi:10.2478/v10078-012-0035-3

Delshad M, Ghanbarian A, Mehrabi Y, Sarvghadi F, Ebrahim K. Effect of Strength Training and Short-term Detraining on Muscle Mass in Women Aged Over 50 Years Old. Int J Prev Med. 2013 Dec;4(12):1386-94. PubMed PMID: 24498494; PubMed Central PMCID: PMC3898444.

Devienne, M.F., Guezennec, C.Y. (2000). Energy expenditure of horse riding. European Journal of Applied Physiology, 82, 499-503.

Douglas, J.L., Price, M. and Peters, D.M. (2012). A systematic review of physical fitness, physiological demands and biomechanical performance in equestrian athletes. Comparative Exercise Physiology, 8(1), 53-62.

Exercise Instructions. (2014). Retrieved March 23, 2014, from http://www.theraband.com/instructions.php

Federation Equestre International. (2013). Retrieved January 18, 2014 from http://www.fei.org/fei/your-role/organisers/dressage/tests

Kibler, W.B., Press, J. and Sciascia, A. (2006). The role of core stability in athletic function. Sports Medicine, 36(3), 189-198.

Kiens, B., Birgitta, E.G., Christensen, N.J., Saltin, B. (1992) Skeletal muscle substrate utilization during submaximal exercise in man: effect of endurance training. Journal of Physiology, $469,459-478$. 
Lagarde, J., Peham, C., Licka T. and Kelso, J.A.S. (2005) Coordination dynamics of the horserider system. Journal of Motor Behavior, 37(6), 418-424.

Licka, T., Kapaun, M. and Peham, C. (2004) Influence of rider on lameness in trotting horses. Equine vet. J. 36, 734-736.

Lovett, T., Hodgson-Tole, E. and Nankervis, K. (2005). A preliminary investigation of rider position during walk, trot and canter. Equine and Comparative Exercise Physiology, 2, 71-76.

Martins WR, de Oliveira RJ, Carvalho RS, de Oliveira Damasceno V, da Silva VZ, Silva MS. Elastic resistance training to increase muscle strength in elderly: a systematic review with meta-analysis. Arch Gerontol Geriatr. 2013 Jul-Aug;57(1):8-15. doi: 10.1016/j.archger.2013.03.002. Epub 2013 Apr 4. Review. PubMed PMID: 3562413.

Meyers, M.C., Sterling, J.C. (2000). Physical, hematological, and exercise response of collegiate female equestrian athletes. The Journal of Sports Medicine and Physical Fitness, 40, 131 138.

Meyers, M.C. (2006). Effect of equitation training on health and physical fitness of college females. European Journal of Applied Physiology, 98, 177-184.

Moritani T, deVries HA. Neural factors versus hypertrophy in the time course of muscle strength gain. Am J Phys Med. 1979 Jun;58(3):115-30. PubMed PMID: 453338.

Movahed M, Izumi H, Higuchi Y, Lai V, Theppitak C, Kumadini G, Kumashiro M. The effects of static trunk flexion on oxygenation and electromyographic activity of erector spinae muscles. J UOEH. 2012 Mar 1;34(1):15-25. PubMed PMID: 22428455

National economic impact of the U.S. horse industry. (2005) Retrieved January 20, 2014 from http://www.horsecouncil.org/national-economic-impact-us-horse-industry

Peham, C., Licka, T., Kapaun, M. and Scheidl, M. (2001). A new method to quantify harmony of the horse-rider system in dressage. Sports Engineering, 4. 95-101.

Pescatello, L.S. (2014) ACSM's guidelines for exercise testing and prescription. Wolters Kluwer/Lippincott Williams and Wilkins Health.

Roberts, M. Shearman, J. and Marlin, D. 2009. A comparison of the metabolic cost of the three phases of the one-day event in female collegiate riders. Comparative Exercise Physiology 6: 129-135.

Schils, S.J., Greer, N.L., Stoner, L.J. and Kobluk, C.N., 1993. Kinematic analysis of the equestrian-walk, posting trot and sitting trot. Human Movement Science 12:693-712. 
Symes, D. and Ellis, R.,2009. A preliminary study into rider asymmetry within equitation. The Vetrinary Journal 181:34-37.

Rohmert, W. Problems of determination of rest allowances Part 2: determining rest allowances in different human tasks. Appl Ergonom. 1973 4(3):158-162.

Schils, S.J., Greer, N.L., Stoner, L.J. and Kobluk, C.N. (1993). Kinematic analysis of the equestrian- walk, posting trot and sitting trot. Human Movement Science, 12, 693-712.

Symes, D. and Ellis, R. (2009). A preliminary study into rider asymmetry within equation. The Veterinary Journal, 181. 34-37.

Terada, K. (2000). Comparison of head movement and EMG activity of muscles between advanced and novice horseback riders at different gaits. Journal of Equine Science, 11(4), 83-90.

Terada, K., Mullineaux, D.R., Lanaovaz, J., Kato, K. and Clayton, H.M. (2004). Electromyographic analysis of the rider's muscles at trot. Equine and Comparative Exercise Physiology, 1(3), 193-198.

Tests. (2014). Retrieved March 28, 2014 from http://www.usdf.org/about/aboutdressage/competition/tests.asp

Thompson, W.R., Gordonm N.F. and Pescatello, L.S. (2010). ACSM's Guidelines for Exercise Testing and Prescription, Eighth Edition. Philadelphia, PA: Lippincott Williams \& Wilkins.

Westerling, D. (1983). A study of physical demands in riding. European Journal of Applied Physiology, 50. 373-382.

Zion, A.S., Meersman, R.D., Diamond, B.E., Bloomfield, D.M. (2003). A home-based resistance-training program using elastic bands for elderly patients with orthostatic hypotension. Clinical Autonomic Research, 13: 286-292. 